Rhode Island College

Digital Commons @ RIC

$5-15-2021$

\title{
Making Sense of Acute Stress: Psychological Adjustment in Meaning Making
}

Kristen Diann Petagna

Follow this and additional works at: https://digitalcommons.ric.edu/etd

Part of the Psychology Commons

\section{Recommended Citation}

Petagna, Kristen Diann, "Making Sense of Acute Stress: Psychological Adjustment in Meaning Making" (2021). Master's Theses, Dissertations, Graduate Research and Major Papers Overview. 342.

https://digitalcommons.ric.edu/etd/342

This Thesis is brought to you for free and open access by the Master's Theses, Dissertations, Graduate Research and Major Papers at Digital Commons @ RIC. It has been accepted for inclusion in Master's Theses, Dissertations, Graduate Research and Major Papers Overview by an authorized administrator of Digital Commons @ RIC. For more information, please contact digitalcommons@ric.edu. 

MAKING SENSE OF ACUTE STRESS: PSYCHOLOGICAL ADJUSTMENT IN MEANING MAKING

\author{
A Thesis Presented by \\ Kristen D. Petagna
}

2021

Approved:

\begin{tabular}{lc} 
Kymberlee O'Brien & $5 / 1 / 2021$ \\
Adviser and Committee Chair & \\
Katherine Lacasse & $5 / 1 / 2021$ \\
\hline Committee Member & \\
Karina Brabeck & $5 / 1 / 2021$ \\
\hline Committee Member & \\
Bethany Lewis & $5 / 1 / 2021$ \\
\hline Department Chair & \\
Joan Dagle & $5 / 1 / 2021$ \\
\hline
\end{tabular}

Dean of School 


\title{
MAKING SENSE OF ACUTE STRESS: PSYCHOLOGICAL ADJUSTMENT IN MEANING
} MAKING

By Kristen D. Petagna

\author{
A Thesis Submitted in Partial Fulfillment \\ of the Requirements for the Master of Psychology in \\ The Department of Psychology \\ The School of Arts and Sciences \\ Rhode Island College
}

2021 


\begin{abstract}
The current study utilized an experimental design to investigate violations of global meanings, perceived stress, positive affect and negative affect in the context of meanings made from a stressful situation. Additionally, meanings made were investigated as a moderator of the relationship between those variables. A sample of 40 participants completed the experiment and the questionnaires. Half of the participants were randomly assigned to either the control group or the experimental group. Participants responded to a variety of measures including, perceived stress, positive and negative affect, positive cognitive emotional regulation strategies (meaning making attempts), meanings made, global meaning measures such as self-esteem and beliefs about control, and other demographic information. Participants in the experimental group underwent a virtual version of the Trier Social Stress Task to induce stress, while participants in the control group read a text. Results indicated that negative affect was increased after the stressful task compared to the end of the experiment and that positive affect after completing the stressful task decreased from positive affect measured when anticipating the task. The current study has important potential implications for completing the Trier Social Stress Task remotely, and for examining the role of acute stress in the meaning making model.
\end{abstract}




\section{Acknowledgements}

I would like to thank my thesis committee chair, Dr. Kymberlee O'Brien, whose expertise was invaluable in formulating the research questions and methodology. Thank you for encouraging my ideas and for allowing me to grow as a research scientist. I would also like to thank Dr. Katherine Lacasse for serving on my thesis committee. Your insightful feedback pushed me to sharpen my thinking and brought my work to a higher level. I would also like to acknowledge Kalina Brabeck for her wonderful collaboration and for serving on my thesis committee. Additionally, I would like to thank the faculty members in the Department of Psychology at Rhode Island College, for the inspiration and mentorship to attend graduate school and to pursue an academic career. Specifically, I would like to thank Dr. David Sugarman for taking a calculated risk when he decided to mentor an unseasoned undergraduate in psychological research. I am extremely grateful for my parents, Mike and Cindy Petagna. Without their love, prayers and sacrifices I would not have reached this monumental milestone in my educational journey. I would also like to thank William Turbitt for providing me with unfailing support and continuous encouragement throughout my years of study and through the process of researching and writing this thesis. Finally, I could not have completed this thesis without the support of my friend and colleague Alex Dickie who aided in study recruitment and provided stimulating discussions as well as happy distractions to rest my mind outside of my research. 


\section{Table of Contents}

Making Sense of Acute Stress: Psychological Adjustment in Meaning Making ............... 1

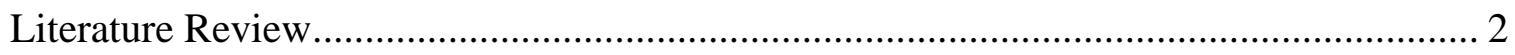

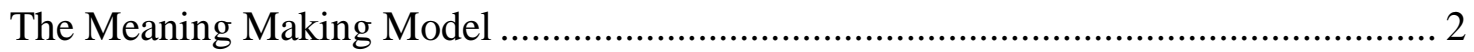

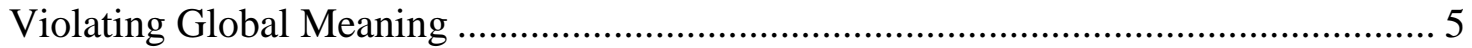

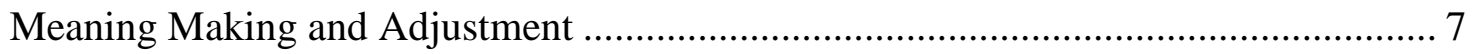

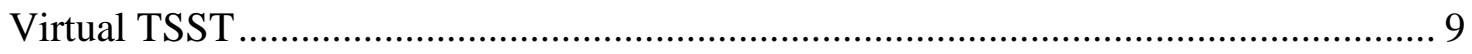

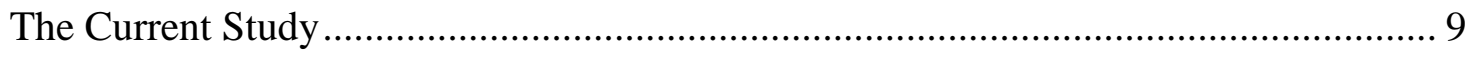

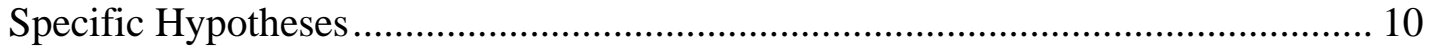

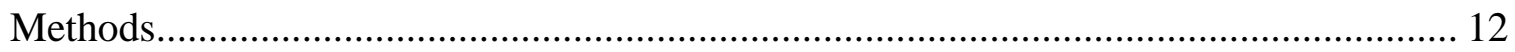

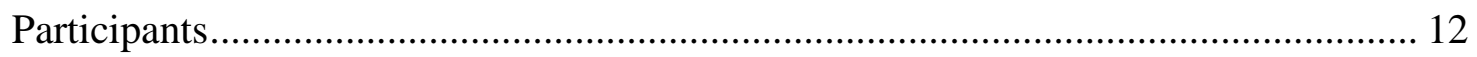

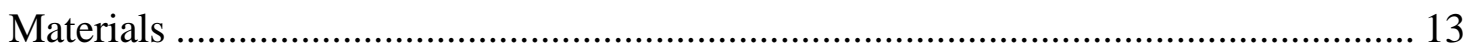

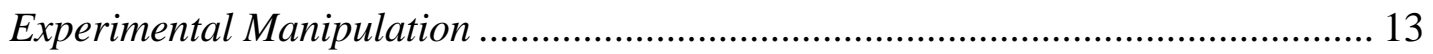

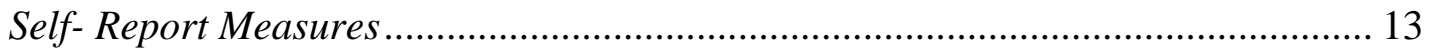

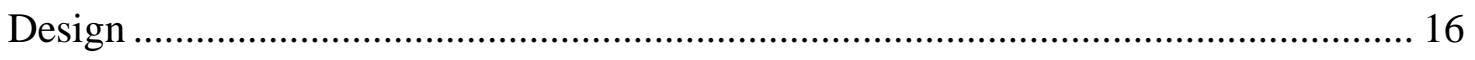

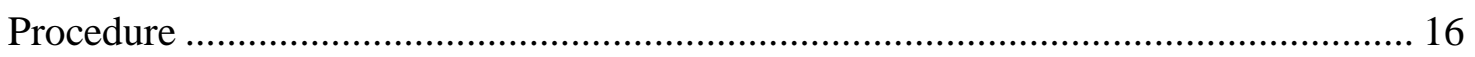

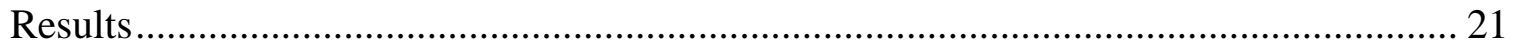

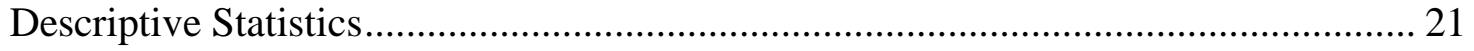




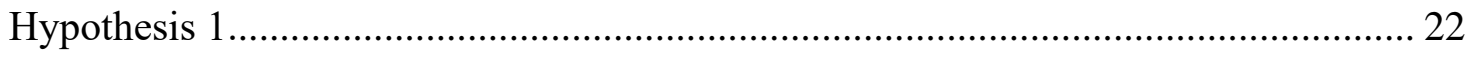

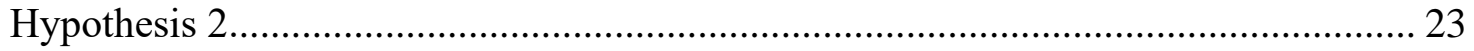

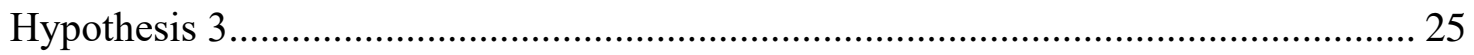

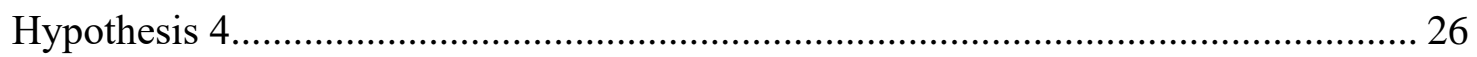

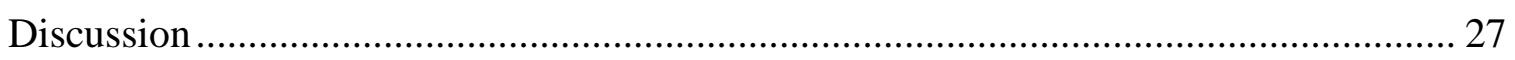

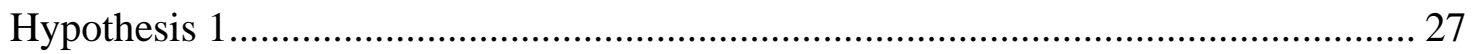

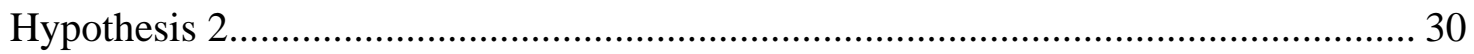

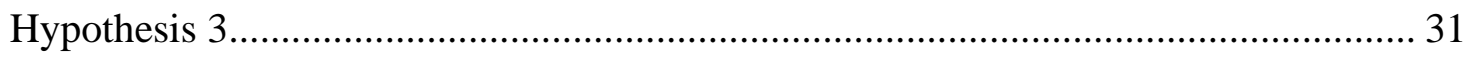

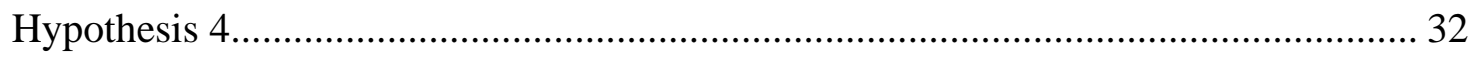

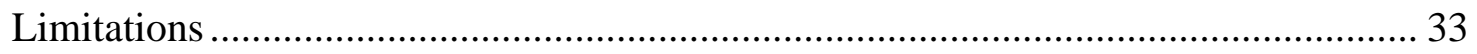

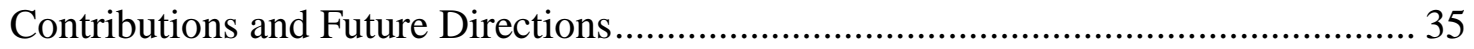

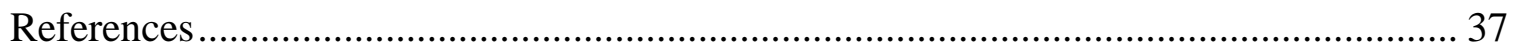

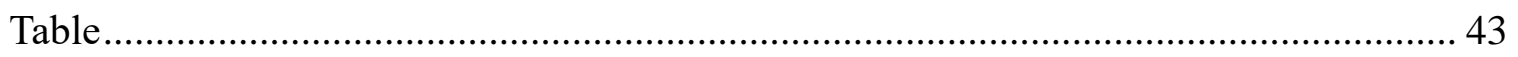

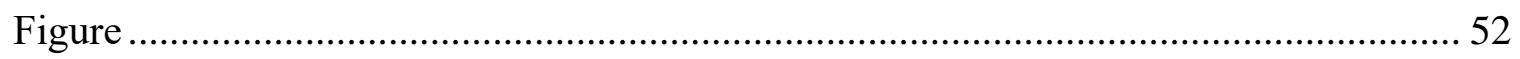

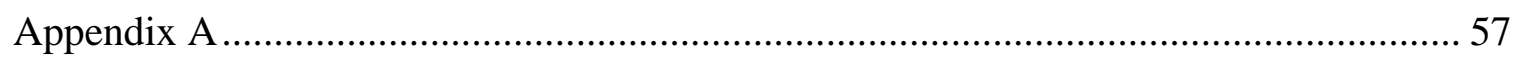

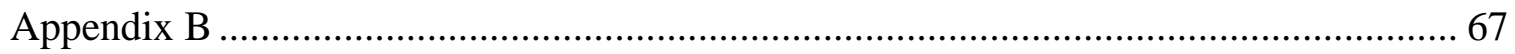

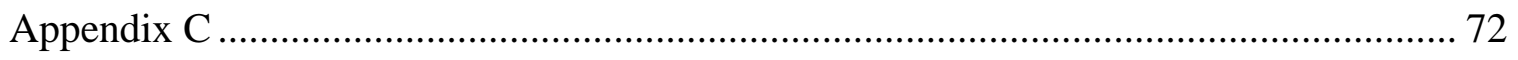




\section{Making Sense of Acute Stress: Psychological Adjustment in Meaning Making}

The human quest to find meaning from the adversity life can bring is a fundamental human motivation. Making meaning after adversity is a prevalent theme in psychology, philosophy, religion, and personal narratives. Philosopher Friedrich Nietzsche $(1889$, p. 6$)$ is recognized for the quote, "If we have our own why in life, we shall get along with almost any how." The apostle Paul from the Bible made the bold claim that suffering produces endurance, character, and even hope (Romans 5:3-5, New International Version). Holocaust survivor Viktor Frankl (1985) wrote a book about his journey to find meaning during the dehumanizing experience of being a prisoner in a concentration camp during the Holocaust. It has been a long discussion of trying to understand suffering.

Making meaning after adversity is the process of trying to comprehend or make sense of a stressful event (Park, 2013). When an event defies our expectations about our world, we often try to make sense of or comprehend the event (Park, 2010). Making meaning from a stressful event has been thought of as a common approach in coping with stress (Park, \& Folkman, 1997). While a stressful event can produce psychological distress, it can also provide the opportunity for personal growth through a search for meaning from aftermath of the stressful event (Tedeschi \& Riffle, 2016). Searching for meaning is often related to positive adjustment (e.g., Affleck et al. 1985; Davis et al., 1998; Sears et al., 2003; Silver et al., 1983; Taylor, 1983), although this is not a guaranteed outcome and the search for meaning is also often related to negative adjustment (e.g., Bonanno et al., 2005; Clark et al., 1991; Dollinger, 1986; Downey et al., 1990; Park, 2010; Roberts et al., 2006). Given the salience of making meaning out of stress, it is essential to examine the psychological processes involved, and whether the final, personal meaning will lead to positive adjustment from a stressful situation. 


\section{Literature Review}

\section{The Meaning Making Model}

The meaning-making model described by Park (2010) postulates that people possess general orienting systems that rely on cognitive frameworks that help them interpret their experiences (See figure 1). This orienting system is known as one's global meaning. When a person is presented with a situation that has the potential to threaten one's global meaning, the event is appraised, and the individual assigns the event meaning. The proportion of discrepancy between the appraised event's meaning and one's global meaning is proportional to the amount of distress one experiences. In theory, the distress experienced from this discrepancy should lead to one trying to make meaning. These meaning making attempts can lead to a product of meaning made which should lead to better adjustment.

Global meaning includes beliefs about order, having a sense of purpose, and maintaining future goals (Park, \& Folkman, 1997). Every experience one encounters is shaped by this value structure including individual's thoughts and behaviors. Not only are one's present actions influenced by their global meaning system, but how they interpret their past, and their expectations of the future are also interpreted through this framework. This worldview has been developing since infancy and continues to be shaped by an individual's personal experiences (Janoff-Bullman, 2010).

Global beliefs, one part of our global meaning systems, can be fundamental assumptions about the world, the self, and the self in the world such as broad views regarding justice, control, predictability, coherence, and an individual's self-views (Park, 2010). These global beliefs provide a sense of order and comprehensibility about our world (Park, 2016). One example of a global belief is the perception of control in one's life. Often times, individuals have a biased 
illusion of control believing they can control chance events (Langer, 1975; Taylor \& Brown, 1988). For example, someone could believe that they can control being let go from their job by working hard and performing well. Unfortunately, a person can lose their job even if they work hard because of events outside of their control such as a bad economy.

Global goals, the second piece of one's global meaning, are desired outcomes and can include aspirations, values and strivings (Park, 2010). Not only are global goals things we wish to achieve, but processes we are currently accomplishing that we wish to maintain. For example, one global goal one might wish to attain is to have a career in a chosen field. One example of preserving a global goal would be maintaining a relationship that one already has. Other global goals include physical self-preservation and social self-preservation (Dickerson \& Kemeny, 2004). Social self-preservation theory posits that maintaining a positive social self is a central human goal (Gruenewald et al., 2004). This includes one's self-esteem or social status. These global goals provide a sense of purpose in our life (Park, 2016).

The third part of global meaning is having a sense of subjective meaning or purpose in one's life (Park, 2010). This part of global meaning is broadly defined as "feeling" meaningful and feeling like one has purpose in their life. The combination of working towards one's global goals in a way that is consistent with their global beliefs makes up this subjective sense of meaning one can feel (Park, 2016).

Situational meaning is the meaning given to a particular environmental encounter (Park, 2010). When a potentially stressful situation occurs, the event's meaning is appraised. An individual implicitly determines whether the event poses a threat including if it will cause harm or loss, or if it presents a challenge, which has a more positive connotation. Whether the implicit meaning is determined to be a threat or a challenge, the individual will then examine their 
resources. The appraised situational meaning of the stressor is compared to one's global meaning system. If the situational meaning is perceived as discrepant from one's global meaning, then distress arises. An example of this discrepancy could be when a situation arises that one does not have as much control of as they thought they would. If someone has the global belief that they can control outcomes by working hard, but they appraise a current situation as uncontrollable even though they are working hard, the situational meaning is discrepant from their global meaning.

Attempting to make meaning refers to the process people engage in to reduce the discrepancy between the situational meaning and one's global meaning (Park, 2010). This process involves one trying to make sense out of the event. Meaning making that involves changing situational appraised meaning to be more consistent with existing global meaning has been termed assimilation, and that which involves changing global beliefs or goals has been termed accommodation (Joseph \& Linley, 2005; Parkes, 2001). This process can be either an automatic or a deliberate processing. Examples of automatic processing are intrusive thoughts about the event, avoiding reminders of the event, unintentionally shifting one's goals, and other processes that occur that are not deliberate. Examples of deliberate processing include positive reappraisal of the event, downward comparisons with those who are worse off, searching for an acceptable reason of why the event occurred, and looking for benefits. These processes are known as meaning making attempts. These processes may or may not resolve the discrepancy between one's global meaning and the appraised meaning of the event. If it does not, then no new meaning is made, and they simply ruminate about the event.

Meanings made are the products of meaning making attempts (Park, 2010). Meanings made occur when the discrepancy between one's global meaning and the appraised meaning of 
the event is reduced. This final product of making meaning should reduce distress symptoms. Meanings made can include making sense out of the event, accepting the event, reattributing the event, perceptions of growth or positive change from the event (posttraumatic growth), a changed identity from the event, reappraising the meaning of the stressor, changing global goals, and/or a changed sense of meaning or purpose in life. Continuing with the example of control, one can make meaning out of an uncontrollable situation by changing their global beliefs about control by accepting that there are things outside of one's control.

Sometimes meanings made can be negative (Park, 2010). For example, after a car accident one could use accommodation by changing former global beliefs to be: "The world is not safe." Or one could change the situational meaning of the event to think: "I am to blame" (even if one is not to blame). According to the meaning making model these shifts in beliefs are products of meaning made even though the valence is negative. It is inconclusive if these negative meanings lead to worse adjustment or not.

\section{Violating Global Meaning}

The meaning making model posits that distress occurs when situational meaning is discrepant from one's global meaning (Park, 2010). However, little testing has been done on the meaning making model itself and to the author's knowledge no research has actually tested whether a stressor actually violates one's global meaning system. Instead, researchers have examined current global beliefs and have tried to retrospectively assess what those beliefs may have been pre-trauma (Epstein, 1991; Foa et al 1991). An acute laboratory psychological stressor that violates global goals such as maintaining the social self and also violating global beliefs about control would enable researchers to see if stressors can actually violate one's global meaning and to explore the process of making meaning from the discrepancy. 
It is likely that if these laboratory stressors actually violate one's global meaning system, it would lead to a reaction of the hypothalamic-pituitary-adrenocortical axis (HPA axis). The HPA axis is the central stress response system and when activated it releases stress hormones such as cortisol (Stephens \& Wand, 2012). Psychological stressors such as the Trier Social Stress Task (TSST) activate the HPA axis stress response (Dickerson \& Kemeny, 2004). In addition to the physiological stress response, the TSST also triggers a psychological stress response (Finan et al., 2011). Mood is also affected by the TSST in that negative affect increases and positive affect decreases (Boesch et al., 2014). Distress symptoms often increase, but women report more distress and negative affect than men in the TSST (Fehm-Wolfsdorf et al., 1999).

The TSST is a laboratory task that induces social evaluative threat. The TSST has different variations, but the procedure generally involves participants preparing for a 5-minute speech that is often framed as a pitch for a job interview. The paper the participants use to take notes on and to prepare for the speech is taken away unexpectedly, and the participants are asked to begin giving their 5-minute speech or interview pitch to a panel of evaluators. The participant stands in front of a microphone, a video camera, and a panel of evaluators who are sitting at a desk. The evaluators remain neutral or can make negative facial features the whole time and do not comment during the speech. The evaluators will occasionally take notes during the speech. If the participant stops talking within 5 minutes, they are asked to continue. Lastly the participant is asked to complete a mental math task such as subtracting 13 from 2,043 for 5 minutes out loud. If the participant makes a mistake they are asked to start over until the time runs out.

The reason why the TSST is so stressful for people is because it threatens central goals of social self-preservation by using social evaluation and uncontrollability (Dickerson \& Kemeny, 2004). Threats to self-esteem, self-value, or social status threaten the social self. The TSST 
threatens one's social self by evaluators giving negative or no feedback while the participant is giving their best effort in a speech. The participant might experience decreases in self-esteem and may feel socially rejected. Uncontrollability heightens the stress response because it hinders one from attaining the goal of preserving the social self. The TSST also decreases controllability because no matter how well the participant tries to do in the interview speech, the negative feedback or no feedback is received and because their notes to prepare for the speech are taken away. The participant can do nothing to change the situation which amplifies the threat to their social self-preservation goal. When the social self is threatened and the way to attain the goal is impeded, it activates the HPA axis stress response.

\section{Meaning Making and Adjustment}

Searching for meaning is often related to positive adjustment (e.g., Affleck et al. 1985;

Davis et al., 1998; Sears et al., 2003; Silver et al., 1983; Taylor, 1983), although this is not a guaranteed outcome and the search for meaning is also often related to negative adjustment (e.g., Bonanno et al., 2005; Clark et al., 1991; Dollinger, 1986; Downey et al., 1990; Park, 2010; Roberts et al., 2006). Studies that examine meaning making attempts and meaning made often show that meaning making attempts produce distress, but the meaning making product is related with reduced distress (Park, 2010). Searching for meaning is a sign that there is still a discrepancy between one's global meaning and situational meaning. When one's situational meaning is discrepant with one's global meaning, the discrepancy has been shown to create psychological distress symptoms (Plaks et al., 2005). The motive to reduce this discrepancy and the resulting negative adjustment are driven by meaning making attempts (Park, 2010). Therefore, the discrepancy drives distress even if the search for meaning is occurring. When a 
final product of meaning is made, the discrepancy is reduced and there is successful adjustment and decreased distress.

Theorists argue that successful adjustment can only occur from a product (meaning made) and not just the process (Park \& Folkman, 1997; Segerstrom et al., 2003). Until a meaning making attempt results in a change or a product that reduces the discrepancy between global meaning and situational meaning, distress and negative affect are positively related to meaning making attempts. Several studies have shown a relationship between a product of meaning and reduced distress (Draucker, 1989; Keese et al. 2008; Koss \& Figueredo, 2004) however to the author's knowledge a causal relationship has not been established.

\section{Methodological Improvements}

Past studies that have examined the relationship between a product of meaning and distress have been retrospective and correlational. Such studies ask participants to retrospectively report whether or not they made meaning out of a past stressful event and then examine whether a product of meaning made relates to lower stress, distress, and other self-report adjustment measures (Draucker, 1989; Keese et al., 2008; Koss \& Figueredo, 2004). The use of retrospective self-reports has been criticized for its credibility and accuracy (Paulhus \& Vazire, 2007). The meaning making literature has called for creative alternative approaches to self-report to test the model (Park, 2010).

One previous study did manipulate stress to see if individuals who made meaning would report decreased stress (Mihara et al., 2020). Specifically results showed that from 27 university students the individuals who were higher in self-reported personal growth, which is one possible product of meaning making, reported lower perceived stress than a group low in personal growth after completing the TSST. Other products that can be obtained from meaning making such as 
finding a positive, and acceptance of the stressor and their relationship to adjustment can be examined in casual way to support the retrospective self-report research.

\section{Virtual TSST}

During a global health pandemic such as COVID-19, virtual versions of experiments may be utilized when in-person data collection cannot happen. During the pandemic, virtual interviews and other social interactions have become increasingly prevalent (Jones, \& Abdelfattah, 2020). The same judgment of social value and risk to loss of self-esteem that happens in a face-to-face interaction can happen over an electronic interview. Virtual versions of the Trier Social Stress Test involving a computer screen and headphones have been shown to reliably produce a significant HPA axis acute stress response (Fallon et al., 2016). A pilot study used an electronic version of the TSST (E-TSST) to examine if a stress response could be elicited virtually over a video platform (Hawn et al., 2015). The E-TSST produced a significant physiological and self-reported stress response compared to the electronic control condition and subjective distress reported from the E-TSST was similar to the traditional TSST.

\section{The Current Study}

The current study is designed to experimentally manipulate stress using the virtual TSST. It will be the first study to examine the causal links between the factors in the meaning-making model and will repeatedly measure different adjustment outcomes before and after the stress task at different time points to see when changes occur.

The current study predicts that an acute psychological stressor such as a virtual version of the TSST will violate one's global meaning, specifically violating global beliefs about control and global goals of social self-preservation such as self-esteem. Self-esteem and control beliefs should be significantly reduced after participants experience the TSST stressor in the 
experimental group. Causality about stress causing a discrepancy between one's global meaning and the situational meaning can be inferred because of the experimental design. Alternately, the control group who will not go through a stress task should not experience a discrepancy and should have consistent self-esteem and control beliefs before and after the non-stressful task.

The current study also predicts that meanings made from the stressor will decrease subjective reports of stress and negative affect produced by the stressor and that it will increase positive affect that was originally decreased from the stress task. The TSST will produce increased negative affect and perceived stress and decreased positive affect compared to the control group. The stress that is produced by the TSST will lead to increased meaning making attempts compared to the control group who does not go through the stress task. Since the control group's global meaning is not discrepant from their situational meaning, they will not experience increased negative affect and perceived stress and decreased positive affect and will not need to attempt to make meaning. If the participant successfully creates a new product of meaning made, it should lead to decreased perceived stress and negative affect and increased positive affect.

\section{Specific Hypotheses}

\section{Hypothesis 1}

In the experimental group, global meaning scores reported after the acute psychological stressor (G2) will be lower than the baseline global meaning scores (G1) (See figure 2). Specifically, self-esteem, personal control, interpersonal control, and socio-political control will be lower at G2 than G1 scores. In the control group, global meaning scores after the non-stressful task (G2) will not significantly differ from baseline global meaning sores (G1). Specifically, self- 
esteem, personal control, interpersonal control, and socio-political control will not differ at G1 or G2.

\section{Hypothesis 2}

In the experimental group, the virtual version of the TSST will produce increased reports of subjective stress compared to the control group that completes a non-stressful task.

H2.1. In the experimental group, negative affect and perceived stress scores measured during the anticipatory/preparation period of the acute psychological stressor (T2) will increase from baseline negative affect and perceived stress scores (T1). Negative affect and perceived stress measured after the TSST tasks are completed (T3) will continue to increase from the anticipatory/preparation period (T2). Negative affect and perceived stress scores measured at the end of the experiment (T4) will not be significantly different from baseline (T1).

Positive affect will decrease during the anticipatory/preparation period of the acute psychological stressor (T2) from baseline positive affect scores (T1). Positive affect (T3) will continue to decrease after the TSST tasks are completed from the preparation period (T2). Positive affect measured at the end of the experiment (T4) will not be significantly different from baseline (T1).

H2.2. In the control group, negative affect, positive affect and perceived stress scores after the instruction period (T2), after the non-stressful task (T3), and at the end of the experiment (T4) will not significantly differ from baseline negative affect, positive affect and perceived stress scores (T1).

\section{Hypothesis 3}

The experimental group will have significantly higher scores on the positive subscales of the Cognitive Emotion Regulation Questionnaire (indicating more meaning making attempts) 
than the control group and will report a product of meaning made more often than the control group.

\section{Hypothesis 4}

The experimental group will report increased perceived stress and negative affect from time 2 to time 3 . This relationship will be moderated by a report of meaning being made. The experimental group will report decreased positive affect from time 2 to time 3 . This relationship will be moderated by a report of meaning being made. Those who report a product of meaning made will have decreased perceived stress and negative affect and increased positive affect. The control group will not have increased perceived stress and positive and negative affect from time 2 to time 3 . There will be no products of meanings made in the control group.

\section{Methods}

\section{Participants}

Participants were recruited through Rhode Island College's Introduction to Psychology participant pool, and through posting a recruitment flyer to groups and pages on social media platforms. Participants in Rhode Island College's Introduction to Psychology participant pool received course credit and one ticket entered into a lottery to be randomly drawn to win an Amazon gift card. Participants recruited that were not in this course received two tickets entered into a lottery to be randomly drawn to win an Amazon gift card. There were three random drawings. The first was for a $\$ 50$ Amazon gift card and the following two were for $\$ 25$ Amazon gift cards.

A total of 40 participants were recruited for the present study. The 40 participants were randomly assigned to either the experimental group or the control group with 20 participants in each group. Participants were excluded if they were under the age of 18, did not speak English, 
or did not have access to web camera, a microphone, and access to a computer with Zoom Video Communications. Participants ranged in age from 18-82 years old $(M=30.85, S D=15.903, M d n$ $=25)$ and $67.5 \%$ of the sample identified as female. A majority of the sample was White $(60 \%)$ and the majority of participant's highest level of education is High School (40\%) and the second highest levels are Bachelor's degree (22.5\%) and Master's or professional degree $(22.5 \%)$.

\section{Materials}

\section{Experimental Manipulation}

Experimental Condition's Trier Social Stress Task. A modified version of the Trier Social Stress Task was conducted virtually over Zoom Video Communications (Kirschbaum et al., 1993). The Trier Social Stress Task is a motivated performance task that elicits a stress response in social evaluative situations. It consists of a short preparation period followed by a free speech task and a mental arithmetic task in front of a researcher while being video recorded. Lastly there is a recovery period.

Control Condition's Reading. Participants read chapter 10.1 Wave Basics in an introduction to oceanography textbook (Webb, 2019).

\section{Self- Report Measures}

Demographics. Participants responded to a demographic questionnaire (see Appendix A) at the beginning of the survey. Items collected information on participants' age, gender identification, educational level, and ethnicity.

Global Meaning. Two types of global meaning were assessed: control beliefs and selfesteem. Control beliefs were measured by the Spheres of Control Scale-3 (Paulhus, 1990). This is a 30 item Likert-type scale with three spheres of control subscales: personal achievement control, interpersonal relations control, and socio-political world control. These subscales will be 
three distinct control beliefs scores. Sample questions include, "I can usually achieve what I want if I work hard for it," and "Most of what happens in my career is beyond my control." Response options range from 1 (disagree) to 4 (neutral) to 7 (agree). Higher scores indicate higher beliefs of perceived control on each of the three subscales. Typical alpha reliabilities for the subscales are .75-.80 (Paulhus, 1983). The alpha reliability obtained from the current sample for personal control was .614, interpersonal control was .765, and socio-political control was .581.

Self-esteem was measured by the Rosenberg Self-Esteem Scale (Rosenberg, 1979). This is a 10 item Likert-type scale. Sample questions include, "On the whole, I am satisfied with myself," and "I wish I could have more respect for myself." Response options range from 1 (Strongly agree), 2 (agree), 3 (disagree) to 4 (Strongly disagree). Higher scores indicate higher self-esteem. Typical alpha reliability is shown to be .92 , indicating excellent internal consistency. The alpha reliability obtained from the current sample was .892.

Meaning Made. Meaning made was assessed by one author developed question that assessed finding a positive from a stressful situation, which is one outcome that can be made in the meaning making process. The question is, "Even if doing a public speaking task was stressful, do you believe that practicing your speech and interview skills today helps you for interviews or public speaking engagements in the future?". Response options include "yes" or "no, this is not applicable". A "yes" response will indicate meaning being made. A "no, this is not applicable" response will indicate that meaning was not made.

Meaning Making Attempts. Meaning-making attempts were measured using five subscales from the Cognitive Emotional Regulation Questionnaire Short Form (CERQ-short; Garnefski, \& Kraaij, 2006). This is an 18-item questionnaire that captures emotional coping strategies when people experience stressful life experiences. The scale has 9 sub-dimensions: 
self-blame, other-blame, rumination, catastrophizing, putting into perspective, positive refocusing, positive reappraisal, self-acceptance, and refocus on planning. To measure meaning making attempts, the self-acceptance, positive refocusing, refocus on planning, positive reappraisal, and putting into perspective subscales will be used because they are the positive and more effective cognitive emotional regulation strategies. Both cognitive and emotional processing are important in meaning making (Park, 2010). The participants in the experimental group were instructed to state how they thought in the following manner while giving the speech they just gave to the interviewer. The participants in the control group were instructed to state how they thought in the following manner while reading the text they just read to the interviewer. Sample questions include, "I feel that I am the one who is responsible for what has happened," and "I think that I cannot change anything about it." Items are measured on a 5-point Likert scale ranging from 1 (almost never) to 5 (almost always). Higher scores on each subscale indicate a higher degree of meaning making attempts for the particular strategy used. Typical alpha reliability scores are .70 and, in many cases, even over .80 . The alpha reliability scores obtained from this sample are .753 for self-acceptance, .849 for positive refocusing, .739 for refocus on planning, .840 for positive reappraisal, and .756 for putting into perspective.

Perceived Stress. perceived stress was measured using the Stress Visual Analogue Scale (Stress VAS; Lesage et al., 2012). This 1 item scale asks participants to rate how stressed they feel in the present moment by sliding the indicator on the scale. The Stress VAS is a 10-point sliding scale. The endpoints are labeled with "none" (0) and "as bad as it could be" (10). Higher scores indicate higher perceived stress.

Positive and Negative Affect. Positive and negative affect was assessed using the Positive and Negative Affect Schedule (PANAS; Watson et al., 1988). This consists of two 10 
item scales. One scale for positive affect and the other scale for negative affect. Participants will rate how they are feeling in the moment. Sample positive affect items include, "enthusiastic," “excited," and "inspired." Sample negative affect items include, "nervous," "jittery," and “irritable." Response options include 1 (very slightly or not at all) to 5 (Extremely). Greater negative affect will be measured by higher scores on the negative affect schedule. Greater positive affect will be measured by higher scores on the positive affect schedule. Typical alpha coefficients range from .83 to .90 for positive affect, and from .85 to .90 for negative affect (Watson, \& Clark, 1999). The alpha coefficients obtained for the current sample are .91 for positive affect and .874 for negative affect.

\section{Design}

The current study utilized a two group (Experimental group v. Control group) betweensubjects experimental design. Participants were randomly assigned to either the experimental group where acute psychological stress will be induced through the virtual Trier Social Stress Task or to a control group where no psychological stress will be induced. In this study, the two groups are the independent variables. Difference scores (T3-T2) in global meaning, meaning making attempts, meanings made, positive and negative affect, and perceived stress are the dependent variables.

\section{Procedure}

Participants signed up for a one-hour appointment to complete the experiment over Zoom Video Communications (See figure 2). As participants signed up, they were randomly assigned to either the experimental or control condition. The participant was then emailed a password protected secure Zoom link to join the meeting. During the Zoom meeting, the researcher went 
over the informed consent form (see Appendix B) and the study procedure with the participant. The participant then read and electronically signed the informed consent form.

An anonymous Qualtrics Survey Software link was sent over the chat box in the Zoom meeting. Participants were either sent a link to the experimental questionnaire or a link to the control questionnaire depending on which condition they were randomly assigned to. The questionnaires were the same for the experimental group and the control group except for the task instructions and task preparation. The researcher and the participant turned off their cameras and muted their microphones while the participant was taking the first questionnaire to give the participant privacy. The questionnaire included demographic questions, global meaning measures (G1), perceived stress, and positive and negative affect measures (T1). The questionnaire then let the participant know if the participant had been assigned to the experimental task or the control task. The participants where then allowed five minutes to prepare for their task. When the five minutes ended, they were allowed to continue with the questionnaire to answer more questions about perceived stress and positive and negative affect (T2). The questionnaire then instructed the participant to let the researcher know that they were done with the questionnaire by unmuting their microphone. The researcher then turned on their camera and unmuted their microphone to go over the task.

The researcher then had the participant perform the experimental or control task depending on what the participant had randomly been assigned to. After the task was performed, the participant was asked to answer questions about positive and negative affect, and perceived stress (T3) and then to take the final questionnaire (G2 and T4). The researcher and the participant turned off their cameras and muted their microphones while the participant was taking the questionnaire to give the participant privacy. The questionnaire included questions 
about meaning making attempts, meanings made, global meaning (G2), positive and negative affect, and perceived stress (T4). The questionnaire then instructed the participant to let the researcher know that they were done with the questionnaire by unmuting their microphone. The researcher then turned on their camera and unmuted their microphone to debrief (see Appendix C) the participant about the study.

Experimental Group. The questionnaire given to participants randomly assigned to the experimental group contained self-report measures that asked participants demographic information, and questions about global meaning (G1), perceived stress, and positive and negative affect (T1). The questionnaire then instructed the participant that they were to take the role of a job applicant who was invited for a personal interview with the company's manager for their ideal job. They were told that after preparing for five minutes, they will have five minutes to introduce themselves to the manager and convince the manager that they are a perfect fit for the job position over Zoom. They were told that their interview speech will be evaluated for its believability and convincingness. They were told that they would be recorded during the interview speech and that the video would be reviewed later.

Qualtrics then provided a timed survey question that has a text box where participants can take notes to prepare for their interview speech. The question had a five-minute countdown clock so the participant could see how much time left they had to prepare. After five minutes the preparation question and all of the notes they typed disappeared. The participant then took a perceived stress and positive and negative affect questionnaire (T2). The questionnaire then instructed the participant to let the researcher know that they were done with the questionnaire by unmuting their microphone. The researcher then turned on their camera and unmuted their microphone. 
The researcher was seated at a desk in front of the web camera. The researcher began recording the Zoom meeting through Zoom and reminded the participant that the meeting recording had started. The researcher asked the participant to "please begin" their interview speech for the next five minutes. The researcher then started a five-minute timer with an alarm. The researcher made mildly negative non-verbal gestures, such as shaking their head, pursing their lips, shrugging their shoulders, and occasionally, took down notes on a clipboard. The participant was allowed to talk uninterrupted for as long as possible. If the participant finished the interview speech before the five minutes was up, the researcher said, "You still have some time left. Please continue!" If the participant ran out of things to say a few times the researcher waited a full 10 seconds then asked a prompted interview questions such as, "why do you think you are better than other applicants?" If the participant only talked about their qualifications or work history the researcher said, "We know your qualifications quite well-please talk about your personality." When the five-minute timer went off the researcher said, "Thank you, your time is up."

The participant was then told that they would have to complete a second task. The participant was not told about this task beforehand. They were asked to count backwards from 2043 in steps of 13 as fast and as precise as they could. On every failed attempt, the participant was asked to restart from 2043. The researcher started a five-minute timer and instructed the participant to begin. When the timer went of the researcher said, "Thank you, your time is up" and instructed them to finish taking the questionnaire. The researcher turned off the video recorder.

The participant was able to mute their microphone and turn off their camera while finishing the last questionnaire. The researcher also turned off their camera and muted their 
microphone until the participant noted to the researcher that they were done with the questionnaire. The participant answered questions about positive and negative affect, perceived stress (T3), meaning making attempts, meanings made, and global meaning (G2). Participants took approximately fifteen minutes to answer the G2 questionnaire before participants were asked about positive and negative affect, and perceived stress a final time (T4). The participant was then instructed to go back to the Zoom meeting and let the researcher know they were done with the questionnaire. The researcher then debriefed the participant about the study.

Control Group. The questionnaire given to participants randomly assigned to the control group contained the same self-report measures that were given to the experimental group except for the task instructions. The participants were asked to give demographic information, and answer questions about global meaning (G1), perceived stress, and positive and negative affect (T1). The questionnaire then informed the participant that they would have to read a text out loud to the researcher for five minutes as a type of personality test for a trait called extraversion.

The participant then took a perceived stress and positive and negative affect questionnaire (T2). The questionnaire then instructed the participant to let the researcher know that they were done with the questionnaire by unmuting their microphone. The researcher then turned on their camera and unmuted their microphone.

The researcher was seated at a desk in front of the web camera. The following tasks were not recorded. The researcher shared their screen with the participant allowing them to see the text. The researcher asked the participant to "please begin" reading the text out loud for the next five minutes. The researcher then started a five-minute timer with an alarm. The researcher remained neutral while the participant was reading. When the five-minute timer went off the researcher said, "Thank you, your time is up." 
The participant was then told that they would have to complete a second task. They were asked to count backwards from 2000 in steps of 10 as fast and as precise as they could. On every failed attempt, the participant was not asked to restart. The researcher started a five-minute timer and instructed the participant to begin. When the timer went of the researcher said, "Thank you, your time is up" and instructed them to finish taking the questionnaire.

The participant was able to mute their microphone and turn off their camera while finishing the last questionnaire. The researcher also turned off their camera and muted their microphone until the participant noted to the researcher that they were done with the questionnaire. The participant answered questions about positive and negative affect, perceived stress (T3), meaning making attempts, meanings made, and global meaning (G2). Lastly the participants were asked about positive and negative affect, and perceived stress a final time (T4). The participant was then instructed to go back to the Zoom meeting and to let the researcher know they were done with the questionnaire. The researcher then debriefed the participant about the study.

\section{Results}

\section{Descriptive Statistics}

Sociodemographic characteristics for participants as a whole and in each condition are reported in Table 1. To assess if there were any participant differences across experimental conditions a series of independent sample t-tests were conducted. Results are reported in Table 2. Results indicated that participants did not differ across conditions based on demographic characteristics of gender identity, educational level, and ethnicity. Participants in the experimental group reported being younger in age than the control group. 
To examine basic relationships between study variables, bivariate correlations were conducted. To see how all of the variables are related to each other, please see Table 3 for all correlations among study variables. Overall, the differences scores (T3-T2) for stress related variables positively correlated with each other and with negative affect, indicating that change in stress and negative affect tended to arise together. Additionally, many of the meaning-making attempt variables were positively correlated indicating that some participants used several of the positive cognitive emotional regulation strategies at the same time.

Hypothesis 1. Several independent samples t-tests were conducted to examine if there were any differences in global meaning scores between the experimental group and the control group. All G1 and G2 global meaning scores did not significantly differ between the experimental group and the control group except G1 socio-political control. G1 socio-political control did significantly differ between the experimental group and the control group. Such that G1 socio-political control was higher in the control group than the experimental group. To see how all of the variables differ between each condition, please see Table 2.

Several paired samples t-tests were conducted to examine whether the global meaning scores of personal control, interpersonal control, socio-political control and self-esteem measured at G2 differed from scores measured at G1 within the experimental group (See Table 4). Contrary to the hypothesis, none of the global meaning scores significantly reduced at G2. G2 personal control did not significantly differ from G1 personal control in the experimental group. G2 interpersonal control did not significantly differ from G2 interpersonal control in the experimental group. G2 socio-political control did not significantly differ from G1 socio-political control scores in the experimental group. G2 self-esteem did not significantly differ from G1 self-esteem scores in the experimental group. 
Several paired samples t-test were conducted to examine whether personal control, interpersonal control, socio-political control and self-esteem measured at G2 differed from scores measured at G1 within the control group (see Table 5). All these findings do not support hypothesis 1 . In support of the hypothesis, G2 personal control did not significantly differ from G1 personal control in the control group. Contrary to the hypothesis, G2 interpersonal control did significantly differ from G1 interpersonal control in the control group. In support of the hypothesis, socio-political control measured at G2 did not significantly differ from G1 sociopolitical control in the control group. Supporting the hypothesis, self-esteem measured at G2 did not significantly differ from G1 self-esteem scores in the control group.

Hypothesis 2. Several independent samples t-tests were conducted to examine if there were any differences between self-reported stress, positive affect and negative affect in the experimental condition and the control condition. Perceived stress, positive affect and negative affect measured at T1, T2, T3, and T4 did not significantly differ between the experimental condition and the control condition (See table 3).

All repeated measures ANOVAs for the experimental group are reported in Table 7 and all repeated measures ANOVAs for the control group are reported in Table 8. A repeated measures ANOVA was conducted to compare the effect of the experimental condition on selfreported stress reported during baseline (T1), an anticipatory period (T2), after the stressful task (T3), and at the end of the experiment (T4). Contrary to the hypothesis, there was not a significant effect of self-reported stress. A repeated measures ANOVA was conducted to compare the effect of the control condition on self-reported stress reported during baseline (T1), an anticipatory period (T2), after the stressful task (T3), and at the end of the experiment (T4). Supporting the hypothesis, there was not a significant effect of self-reported stress. 
Although the ANOVA did not indicate any significant changes in stress, several paired samples t-tests were still conducted to examine if there were any marginally significant differences between different time points of perceived stress in the experimental group. As hypothesized, perceived stress increased at T3 $(M=2.54, S D=.63)$ compared to T1 $(M=2.32$, $S D=.58)$ in the experimental condition, although it was only marginally significant $(\mathrm{t}(15)=-$ $1.78, p=.09)$. In the control condition, no significant differences in perceived stress were reported for any of the time points.

A repeated measures ANOVA was conducted to compare the effect of the experimental condition on positive affect reported during baseline (T1), an anticipatory period (T2), after the stressful task (T3), and at the end of the experiment (T4). Supporting the hypothesis, there was a significant effect of positive affect. A repeated measures ANOVA was conducted to compare the effect of the control condition on positive affect reported during baseline (T1), an anticipatory period (T2), after the stressful task (T3), and at the end of the experiment (T4). Supporting the hypothesis, there was not a significant effect of positive affect.

In the experimental condition, several paired samples t-tests were used to make post hoc comparisons between different time points of positive affect. T3 positive affect reported after the task was significantly different from $\mathrm{T} 2$ positive affect reported at the anticipatory phase in the experimental condition. T1 baseline positive affect was significantly different from T4 positive affect measured at the end of the experiment in the experimental condition. T2 positive affect reported during the anticipatory phase significantly different than $\mathrm{T} 4$ positive affect measured at the end of the experiment in the experimental condition. These results suggest that the experimental condition did have an effect on positive affect. Specifically results suggest that as hypothesized, positive affect was lower after the stressful task was completed (T3) and decreased 
even more at the end of the experiment (T4). Contrary to the hypothesis, positive affect did not decrease while anticipating and preparing for the stress task (T2) from baseline positive affect (T1). Positive affect at any time period did not significantly differ in the control group. Full results are presented in Table 6.

A repeated measures ANOVA was conducted to compare the effect of the experimental condition on negative affect reported during baseline (T1), an anticipatory period (T2), after the stressful task (T3), and at the end of the experiment (T4). Contrary to the hypothesis, there was no significant effect of negative affect. A repeated measures ANOVA was conducted to compare the effect of the control condition on negative affect reported during baseline (T1), an anticipatory period (T2), after the stressful task (T3), and at the end of the experiment (T4). In support of the hypothesis, there was no significant effect of negative effect.

Although the ANOVA did not indicate any significant changes in negative affect, several paired samples t-tests were still conducted to examine if there were any marginally significant differences between different time points of negative affect in the experimental group. Negative affect after the task was completed at T3 was significantly different than at T4, the end of the experiment $(t(18)=-2.60, p=.02)$. Supporting the hypothesis, T3 negative affect after the stress task $(M=18.42, S D=10.63)$ was higher than T4 negative affect reported at the end of the experiment $(M=16.36, S D=10.03)$. In the control group, negative affect did not significantly differ at any time period.

Hypothesis 3. Several independent samples t-tests were used to examine differences on scores on the positive subscales of the Cognitive Emotion Regulation Questionnaire (indicating meaning making attempts) in the control group and the experimental group (see Table 3). There were marginally significant differences between the control group and the experimental group on 
self-acceptance scores. Contrary to the hypothesis, the experimental group had lower selfacceptance scores than the control group. There was a marginally significant difference between the control group and the experimental group on positive refocusing scores. Contrary to the hypothesis, the experimental group had lower positive refocusing scores than the control group. There were marginally significant differences between the control group and the experimental group on putting into perspective scores. Contrary to the hypothesis, the experimental group had lower putting into perspective scores than the control group. There were no significant differences between the control group and the experimental group on refocus planning scores, positive reappraisal scores.

A chi-square test of independence was performed to examine the relationship between a product of meanings made and the condition. The relationship between these variables was significant $\left(X^{2}(1, N=39)=7.46, p=.006\right)$. Supporting the hypothesis, the experimental group $(100 \%)$ was more likely than the control group (65\%) to report a product of meaning made.

Hypothesis 4. A product of meaning made was examined as a moderator of the relationship between the condition (experimental group vs. the control group) and the difference between T3 and T2 negative affect (see Table 9). To test this moderation hypothesis, a two-way ANOVA was used. There was no statistically significant interaction between the condition and a product of meaning made on the negative affect difference score. Contrary to the hypothesis, meaning making did not moderate the relationship between the condition (experimental group vs. control group) and negative affect (see Figure 3).

A product of meaning made was examined as a moderator of the relationship between the condition (experimental group vs. the control group) and the difference between T3 and T2 positive affect (See Table 10). To test this moderation hypothesis, a two-way ANOVA was used. 
There was no statistically significant interaction between the condition and a product of meaning made on the positive affect difference score. Contrary to the hypothesis, meaning making did not moderate the relationship between the condition (experimental group vs. control group) and positive affect (See Figure 5).

A product of meaning made was examined as a moderator of the relationship between the condition (experimental group vs. the control group) and the difference between T3 and T2 perceived stress (see Table 11). To test this moderation hypothesis, a two-way ANOVA was used. There was no statistically significant interaction between the condition and a product of meaning made on the perceived stress difference score. Contrary to the hypothesis, meaning making did not moderate the relationship between the condition (experimental group vs. control group) and perceived stress (see Figure 4).

Although the moderation hypotheses were not supported, the slopes of the figures tend to go in the hypothesized direction. For example, in Figure 3, the people who made a meaning making product in the control condition have lower negative affect than those who did not report a product of meaning made. In Figure 5, people who have a meaning making product in the control group have higher positive affect than people who do not have a meaning making product. These results support the hypothesis. However, in Figure 4, people who have a meaning making product in the control group have higher perceived stress than those who do not have a product of meaning in contrary to the hypothesis.

\section{Discussion}

\section{Hypothesis 1}

The current study aimed to investigate if an acute psychological stressor would influence one's global meaning structure. Specifically, that the experimental groups global meaning scores 
on self-esteem and beliefs about control reported after the stress task (G1) would be lower than baseline global meaning scores (G2). While in the control group, global meaning scores would not change from baseline (G1) to scores reported after the non-stressful task $(\mathrm{G} 2)$. The results did not support the hypothesis. In the experimental group beliefs about personal control, interpersonal control, and socio-political control, and self-esteem did not change after the acute psychological stressor. Results supported the hypothesis that control beliefs regarding personal and socio-political control and self-esteem would not change from baseline (G1) to after the nonstressful task (G2) in the control group. However, contrary to the hypothesis control beliefs regarding interpersonal control decreased from scores reported at baseline (G1) to scores reported after the non-stressful activity (G2) in the control group.

It is possible that the acute psychological stressor was not appraised as threatening and uncontrollable. If the situational meaning of the event is not threatening enough it may not be seen as discrepant from one's global meaning system. Park et al, (2010) suggests that events that are traumatic are the type of stressors that cannot be integrated with one's preexisting global meaning structure. Janoff-Bullman also suggests that people try to conserve and maintain their existing global beliefs and goals rather than change them (2010). Only after a great deal of contradictory evidence would it be enough to provoke change of our fundamental assumptions. Typical or more ordinary events people experience compared to events that are more unexpected, such as trauma, do not change global beliefs. People have experienced giving speeches or doing math often. So, while these tasks may have been stressful, these events are not completely unexpected like a traumatic event would be. Therefore, the TSST is an acute stressor and may not have been unexpected or traumatic enough to violate one's global meaning structure.

The virtual version of the TSST may not have been as stressful as the typical version of the TSST due to differences in the procedure. For example, the typical TSST procedure involves the 
researcher going over the study procedure and then separate actors play the role of the evaluators during the stressful task. Playing both rolls (the researcher and the evaluator) for this virtual version of the TSST may have made the stressful task less stressful because the researcher was already familiar to the participant. Another departure from the typical TSST procedure is that there are usually three evaluators present during the stressful task. Due to COVID-19 social distancing restrictions the virtual version of the TSST conducted in the present study only utilized one evaluator. A panel may be seen as more threatening than a sole evaluator. The typical TSST also has participants stand in front of a microphone in front of the three evaluators while the current study was not able to have participants stand in front of a microphone. Participants were able to sit over Zoom in a room that was familiar to them. This may be less threatening than standing in an unfamiliar room in front of a microphone. Participants may be comfortable talking to a stranger over Zoom because of the increase in the use of Zoom during the COVID-19 pandemic. The differences between the typical TSST procedure and the virtual version of the TSST the current study utilized may have affected the validity of the TSST in inducing a stress response.

It is also possible that the stressful task may still have violated beliefs about control and selfesteem, but that by the time the stressful task was over they were able to make meaning out of the situation before the global beliefs were measured. Even if the task did violate global beliefs, lower scores may not be reported for those beliefs. Just because something violates one's beliefs does not mean that they immediately change/lower their beliefs. Furthermore, some people may have already had low self-esteem or beliefs about control and the stressful experience would not affect or change them because their baseline beliefs are already low.

Contrary to the hypothesis, interpersonal control decreased in the control group. While the control task was intended to be neutral, it may have been less neutral than intended. Comfort level of using Zoom and reading a college level textbook with oceanography jargon to a stranger 
could lead to decreased feelings of interpersonal control. The participants were also told they were being evaluated on how extraverted they were just as the experimental group was, which may have also affected interpersonal control scores.

\section{Hypothesis 2}

The current study also aimed to investigate whether a virtual version of the TSST could produce increased perceived stress and negative affect and decreased positive affect compared to a control group. Results did not support this hypothesis. Negative affect and perceived stress did not increase because of the virtual TSST. However, positive affect did significantly change because of the TSST. Positive affect was the same at T1 and T2, but the decreased at T3 and continued to decrease even lower at T4. This supports the hypothesis that positive affect would decrease from the stressful task. Post hoc analysis did reveal that perceived stress marginally increased from $\mathrm{T} 3$ compared to $\mathrm{T} 1$ in the experimental condition. Additionally, negative affect in the experimental condition was marginally higher at T3 after the task was completed than at T4, the end of the experiment.

One possible reason the virtual version of the TSST did not produce increased perceived stress or increased negative affect could be because of the time point that those variables were measured. Participants completed the task over Zoom and then had to switch their Internet tab to get to the questionnaire to report their stress level and mood levels. By the time the participants got to report their stress levels, they could have already recovered from the task. It has been found that participants rate lower perceived stress after the completion of the task than during the task suggesting that they are already recovering from the stressor (Campbell \& Elhert, 2012). Campbell and Elhert (2012) recommend measuring subjective reports of stress and mood either during the stressful task or immediately after the stressful task. Future research involving a 
virtual version of the TSST should consider measuring subjective measures during and immediately after the task.

Traditionally the TSST produces a robust physiological stress response. The current study was unable to examine physiological measures such as cortisol, heart rate variability, or a galvanic skin response due to having to collect data remotely because of the COVID-19 pandemic. Continuously monitoring heart rate or electrodermal activity would provide faster information about a stress response than subjective measures of stress. Also, subjective measures of stress and their relationship with the TSST have been inconsistent and the emotional response may be too weak to capture (Campbell \& Ehlert, 2012). So, while the virtual version of the TSST may not have produced increased perceived stress, there may still have been a physiological stress response that was not measured. Future research should examine the virtual version of the TSST using physiological biomarkers.

\section{Hypothesis 3}

The current study also aimed to investigate if the stressful task would produce a meaning making product and meaning making attempts. Results did not support this hypothesis. The group that completed the stressful task did not report more meaning making attempts than the control group. Self-acceptance, positive refocusing, and putting into perspective were almost statistically higher for the control group than the experimental group. This finding is the opposite of what was hypothesized. Perhaps the problem was that both the experimental group and control group were both stressed, and both were being socially judged. As discussed earlier the control group may not have been as neutral as was intended. Since the control group stressor was milder, participants may have been able to use these coping strategies more than the experimental condition. Additionally, perhaps the CERQ questionnaire was not the most valid way to measure 
meaning-making attempts. By giving participants a range of coping options to choose from, they may have been influenced to indicate they were using these strategies even if mentally they did not really use these strategies until they were prompted. Perhaps one could use open ended survey questions rather than present the attempts this way, so then participants are not given ideas and they just report what they actually did.

Results did support the hypothesis that the experimental group was more likely to report a product of meaning made than the control group. In fact, every participant in the experimental group reported a product of meaning made. Although contrary to the hypothesis, some participants in the control group reported that they had a product of meaning made. This could be due to the control group not being neutral. If the control group was perceived as stressful then a product of meaning could be made. This could also be due to the way that the product of meaning making was measured. Finding a positive is one way that people can make meaning. However, finding a positive out of a situation can be made even if participants are not stressed. Therefore, finding a positive may not be actually measuring a product of meaning making.

\section{Hypothesis 4}

The current study also aimed to investigate if the experimental group would report increased perceived stress and negative affect and decreased positive affect from the anticipatory phase (T2) to after the stressful task was completed (T3) and that the increased report of perceived stress and negative affect and that the decrease in positive affect would be lessened when a meaning making product occurred. The results did not support this hypothesis. Meaning making did not moderate the relationship between a stressful situation and the report of perceived stress, negative affect, and positive affect. The experimental group only reported that they made a product of meaning. So, if people did not indicate that they did not make meaning 
out of the situation, exploring a meaning making product as a moderator cannot be explored. While it was hypothesized that the experimental group would report more meaning making products than the control group, the lack of variability was not expected. People often want to report positive behavioral changes when there is little to no evidence of actual behavior changes (Frazier et al., 2009). So, while a product of meaning making may not have actually occurred participants will often report the positive perception.

Although the moderation hypotheses were not supported, the slopes of the figures tend to go in the hypothesized direction. For example, in Figure 3, the people who made a meaning making product in the control condition have lower negative affect than those who did not report a product of meaning made. In Figure 5, people who have a meaning making product in the control group have higher positive affect than people who do not have a meaning making product. This is what would be excepted from people who make meaning. However, in Figure 4, people who have a meaning making product in the control group have higher perceived stress than those who do not have a product of meaning. This is not in the hypothesized direction. Perhaps this suggests that stress and a meaning made can co-occur although this goes against past research.

\section{Limitations}

Although the current research used an experimental design it is not without limitations. The study was completed online, and participants could have been distracted while completing the study. Moreover, the COVID-19 pandemic could present a historical threat, possibly resulting in the sample feeling more stressed and overwhelmed than usual, thus increasing increased perceived stress and the dependent variables than what would have been observed without a global pandemic. Additionally, the current research relied on self-reports, and 
participants could have inflated responses by responding with preference toward finding a positive meaning to present themselves in a more socially desirable way, rather than their responses indicating an actual meaning made. Additionally, those who have experienced trauma often experience difficulties with feeling in control, trusting strangers, and generally feeling secure. Therefore, it is possible that participants in the current sample with more extensive histories of adversity may have felt distress in the context of the experimental manipulation, which was not assessed.

The collected sample was not representative in relation to demographic characteristics such as the sample was mostly white, mostly female, and mostly high school graduates. Additionally, the experimental group reported that they were much younger in age than the control group. Differences in individuals are important concerning the TSST as stress responses widely vary among individuals (Birkett, 2011). Differences that have been found to affect the stress response include age, sex, resilience, childhood abuse, and personality traits. As such, the current results may not be generalizable to the population and individual differences may have affected results.

A potential limitation is that the virtual version of the TSST may not have been as stressful as the typical version of the TSST due to differences in the procedure. Playing both rolls (the researcher and the evaluator) for this virtual version of the TSST may have made the stressful task less stressful because the researcher was already familiar to the participant. Participants were able to sit over Zoom in a room that was familiar to them rather than stand in front of a microphone. Also, participants were only evaluated by one person rather than three people. The differences between the typical TSST procedure and the virtual version of the TSST the current study utilized may have affected the validity of the TSST in inducing a stress 
response. Another limitation is that the control condition could have also been a moderately stressful situation in which participants did not have control and were being socially judged. Comfort level of using Zoom and reading a college level textbook with oceanography jargon to a stranger could affect results. One person indicated that they had a reading disability and that they were stressed while reading the text. A larger sample would make some of these outliers less influential.

\section{Contributions and Future Directions}

While having limitations, the current study also made significant contributions to the existing literature. The present study offers a novel approach of using an experimental design to examine if stress disrupts one's global meaning structure, and whether a product of reporting meaning made from a stressor reduces negative psychological reports in addition to testing a virtual version of the TSST. A majority of the previous literature has used retrospective selfreport to examine global meaning and products of meanings made, and the TSST has often been done in a laboratory.

Future research could examine reports of perceived stress and negative and positive affect either during or immediately after the TSST is conducted virtually instead of a delayed measure. In addition to the subjective measures, physiological measures should be examined with a virtual version of the TSST. Salivary cortisol samples could be mailed to participants to measure physiological stress virtually. Heart rate could be monitored by sending participants heart rate monitors to use during the experiment. The addition of physiological measures and more measurements of perceived stress could provide more information about the stress response during a virtual TSST. 
The current study did not find that an acute psychological stressor actually reduced people's global beliefs about control and global goals of self-esteem. While the meaning making model is usually applied to traumatic events, the present study sought to investigate how global beliefs and global goals are affected by acute stress. The reason why events are appraised as stressful is because they are discrepant from our global beliefs. While an acute stressor is not as discrepant from one's global meaning structure as a traumatic event, stress should still be discrepant or else a situation would not be appraised as stressful. However, the smaller the discrepancy between global meaning and situational meaning, the less distress occurs. Acute stress could present less of a discrepancy than traumatic events and therefore one would be able to make meaning much quicker than a traumatic event. The degree of events stressfulness and how that fits into the meaning making model needs to be further studied. Future research could also choose to use a different psychological stressor than the TSST to examine whether global meaning can be violated by stress or other measures to examine meaning making attempts and products. 


\section{References}

Affleck, G., Tennen, H., \& Gershman, K. (1985). Cognitive adaptations to high-risk infants: The search for mastery, meaning, and protection from future harm. American Journal of Mental Deficiency, 89(6), 653-6.

Baron, R. M., \& Kenny, D. A. (1986). The moderator-mediator variable distinction in social psychological research: Conceptual, strategic, and statistical considerations. Journal of Personality and Social Psychology, 51(6), 1173-1182.

Birkett, M. A. (2011). The Trier Social Stress Test protocol for inducing psychological stress. Journal of Visualized Experiments (56), 3238. https://doi.org/10.3791/3238

Boesch, M., Sefidan, S., Ehlert, U., Annen, H., Wyss, T., Steptoe, A., \& La Marca, R. (2014). Mood and autonomic responses to repeated exposure to the Trier Social Stress Test for Groups (TSST-G). Psychoneuroendocrinology, 43, 41-51. https://doi.org/10.1016/j.psyneuen.2014.02.

Bonanno, G. A., Papa, A., Lalande, K., Zhang, N., \& Noll, J. G. (2005). Grief processing and deliberate grief avoidance: A prospective comparison of bereaved spouses and parents in the United States and The People's Republic of China. Journal of Consulting and Clinical Psychology, 73, 86-98. https://doi.org/10.1037/0022-006X.73.1.86

Campbell, J., \& Ehlert, U. (2012). Acute psychosocial stress: Does the emotional stress response correspond with physiological responses?. Psychoneuroendocrinology, 37(8), 1111-1134. https://doi.org/10.1016/j.psyneuen.2011.12.010

Clark L.F., Henry S.M., \& Taylor D.M. (1991). Cognitive examination of motivation for childbearing as a factor in adjustment to infertility. Springer. https://doi.org/10.1007/978-1-4899-0753-0_8 
Davis, C. G., Nolen-Hoeksema, S., \& Larson, J. (1998). Making sense of loss and benefiting from the experience: two construals of meaning. Journal of Personality and Social Psychology, 75(2), 561-574. https://doi.org/10.1037/0022-3514.75.2.561

Dickerson, S. S., \& Kemeny, M. E. (2004). Acute stressors and cortisol responses: A theoretical integration and synthesis of laboratory research. Psychological Bulletin, 130(3), 355-391. https://doi.org/10.1037/0033-2909.130.3.355

Dollinger, S. J. (1986). The need for meaning following disaster: Attributions and emotional upset. Personality and Social Psychology Bulletin, 12(3), 300-310. https://doi.org/10.1177/0146167286123006

Downey, G., Silver, R., \& Wortman, C. (1990). Reconsidering the attribution-adjustment relation following a major negative event: Coping with the loss of a child. Journal of Personality and Social Psychology, 59, 925-940. https://doi.org/10.1037/00223514.59.5.925

Epstein, S. (1991). Impulse control and self-destructive behavior. Alex Publishing Corporation. Fallon, M. A., Careaga, J. S., Sbarra, D. A., \& O'Connor, M. F. (2016). Utility of a virtual Trier Social Stress Test: Initial findings and benchmarking comparisons. Psychosomatic Medicine, 78(7), 835-840. https://doi.org/10.1097/PSY.0000000000000338

Fehm-Wolfsdorf, G., Groth, T., Kaiser, A., \& Hahlweg, K. (1999). Cortisol responses to marital conflict depend on marital interaction quality. International Journal of Behavioral Medicine, 6(3), 207. https://doi.org/10.1207/s15327558ijbm0603_1

Foa, E. B., Ehlers, A., Clark, D. M., Tolin, D. F., \& Orsillo, S. M. (1999). The Posttraumatic Cognitions Inventory (PTCI): Development and validation. Psychological Assessment, 11(3), 303-314. https://doi.org/10.1037/1040-3590.11.3.303 
Frankl, V. E. (1985). Man's Search for Meaning. Simon and Schuster.

Frazier, P., Tennen, H., Gavian, M., Park, C., Tomich, P., \& Tashiro, T. (2009). Does selfreported post-traumatic growth reflect genuine positive change?. Psychological Science, 20(7), 912-919. https://doi.org/10.1111/j.1467-9280.2009.02381.x

Garnefski, N., \& Kraaij, V. (2006). Cognitive Emotion Regulation Questionnaire-development of a short 18-item version (CERQ-short). Personality and Individual Differences, 41(6), 1045-1053. https://doi.org/10.1016/j.paid.2006.04.010

Gruenewald, T. L., Kemeny, M. E., Aziz, N., \& Fahey, J. L. (2004). Acute threat to the social self: Shame, social self-esteem, and cortisol activity. Psychosomatic Medicine, 66(6), 915-924. https://doi.org/10.1097/01.psy.0000143639.61693.ef

Hawn, S. E., Paul, L., Thomas, S., Miller, S., \& Amstadter, A. B. (2015). Stress reactivity to an electronic version of the Trier Social Stress Test: A pilot study. Frontiers in Psychology, 6, 724. https://doi.org/10.3389/fpsyg.2015.00724

Janoff-Bulman, R. (2010). Shattered assumptions. Simon and Schuster.

Jones, R. E., \& Abdelfattah, K. R. (2020). Virtual interviews in the era of COVID-19: a primer for applicants. Journal of Surgical Education, 77(4), 733-734. https://doi.org/10.1016/j.jsurg.2020.03.020

Kirschbaum, C., Pirke, K. M., \& Hellhammer, D. H. (1993). The 'Trier Social Stress Test'-a tool for investigating psychobiological stress responses in a laboratory setting. Neuropsychobiology, 28(1-2), 76-81. https://doi.org/10.1159/000119004

Kudielka, B. M., \& Wüst, S. (2010). Human models in acute and chronic stress: Assessing determinants of individual hypothalamus-pituitary-adrenal axis activity and reactivity. Stress, 13(1), 1-14. https://doi.org/10.3109/10253890902874913 
Langer, E. J. (1975). The illusion of control. Journal of Personality and Social Psychology, 32(2), 311-328. https://doi.org/10.1037/0022-3514.32.2.311

Lesage, F. X., Berjot, S., \& Deschamps, F. (2012). Clinical stress assessment using a visual analogue scale. Occupational Medicine, 62(8), 600-605. https://doi.org/10.1093/occmed/kqs140

Michael, S. T., \& Snyder, C. R. (2005). Getting unstuck: The roles of hope, finding meaning, and rumination in the adjustment to bereavement among college students. Death Studies, 29, 435- 458. https://doi.org/10.1080/07481180590932544

Mihara, K., Okamura, H., Shoji, Y., Tashiro, K., Kinoshita, Y., \& Tsuda, A. (2020). Personal growth and psychobiological stress responsiveness to the Trier Social Stress Test in students. Sustainability, 12(11), 4497. https://doi.org/10.3390/su12114497

Nietzsche, F. (1889). Maxims and Arrows. Twilight of the Idols, 23-27.

Park, C. L. (2010). Making sense of the meaning literature: an integrative review of meaning making and its effects on adjustment to stressful life events. Psychological Bulletin, 136(2), 257-301. https://doi.org/10.1037/a0018301

Park, C. L. (2013). The meaning making model: A framework for understanding meaning, spirituality, and stress-related growth in health psychology. European Health Psychologist, 15(2), 40-47

Park, C. L. (2016). Meaning making in the context of disasters. Journal of Clinical Psychology, 72(12), 1234-1246. https://doi.org/10.1002/jclp.22270

Park, C. L., Mills, M. A., \& Edmondson, D. (2012). PTSD as meaning violation: Testing a cognitive worldview perspective. Psychological Trauma: Theory, Research, Practice, and Policy, 4(1), 66. 
Park, C. L., \& Folkman, S. (1997). Meaning in the context of stress and coping. Review of General Psychology, 1(2), 115-144. https://doi.org/10.1037/1089-2680.1.2.115

Paulhus, D. (1983). Sphere-specific measures of perceived control. Journal of Personality and Social Psychology, 44(6), 1253-1265. https://doi.org/10.1037/0022-3514.44.6.1253

Paulhus, D.L. \& Van Selst, M. (1990). The Spheres of Control Scale: Ten years of Research. Personality and Individual Differences, 11, 1029-1036. https://doi.org/10.1016/01918869(90)90130-J

Paulhus, D. L., \& Vazire, S. (2007). The self-report method. In R.W., Robins, C. R., Fraley, \& R.F., Krueger (Eds.), Handbook of research methods in personality psychology, (pp. 224239). The Guilford Press.

Plaks, J. E., Grant, H., \& Dweck, C. S. (2005). Violations of implicit theories and the sense of prediction and control: Implications for motivated person perception. Journal of Personality and Social Psychology, 88(2), 245-262. https://doi.org/10.1037/00223514.88 .2 .245

Roberts, K. J., Lepore, S. J., \& Helgeson, V. S. (2006). Social-cognitive correlates of adjustment to prostate cancer. Psycho-Oncology, 15,183-192. https://doi.org/10.1002/pon.934

Rosenberg, M. (1979). Conceiving the Self. New York: Basic Books.

Sears, S. R., Stanton, A. L., \& Danoff-Burg, S. (2003). The yellow brick road and the emerald city: benefit finding, positive reappraisal coping and posttraumatic growth in women with early-stage breast cancer. Health Psychology, 22(5), 487-497. https://doi.org/10.1037/0278-6133.22.5.487

Silver, R. L., Boon, C., \& Stones, M. H. (1983). Searching for meaning in misfortune: Making sense of incest. Journal of Social Issues, 39(2), 81-101. 
Stephens, M. A., \& Wand, G. (2012). Stress and the HPA axis: role of glucocorticoids in alcohol dependence. Alcohol Research: Current Reviews, 34(4), 468-483. https://doi.org/10.1111/j.1540-4560.1983.tb00142.x

Taylor, S. E., \& Brown, J. D. (1988). Illusion and well-being: A social psychological perspective on mental health. Psychological Bulletin, 103(2), 193-210.

Taylor, S. E., Wood, J. V., \& Lichtman, R. R. (1983). It could be worse: Selective evaluation as a response to victimization. Journal of Social Issues, 39(2), 19-40. https://doi.org/10.1111/j.1540-4560.1983.tb00139.x

Tedeschi, R. G., \& Riffle, O. M. (2016). Posttraumatic growth and logotherapy: Finding meaning in trauma. International Forum for Logotherapy, 39(1), 40-47.

The Holy Bible, New International Version. (1984). Grand Rapids: Zondervan Publishing House.

The Meaning Making Model. Reprinted from Making sense of the meaning literature: An integrative review of meaning making and its effects on adjustment to stressful life events. (p. 2), by C. L. Park, 2010, Psychological Bulletin. Copyright 2010 by The American Psychological Association.

Watson, D., \& Clark, L. A. (1999). The PANAS-X: Manual for the positive and negative affect schedule-expanded form. University of Iowa Department of Psychological \& Brain Sciences Publications, 1-28. https://doi.org/10.17077/48vt-m4t

Watson, D., Clark, L. A., \& Tellegen, A. (1988). Development and validation of brief measures of positive and negative affect: the PANAS scales. Journal of Personality and Social Psychology, 54(6), 1063-1070. https://doi.org/10.1037/0022-3514.54.6.1063

Webb, P. (2019). Introduction to oceanography. Rebus Community. 
Table 1

Sociodemographic Characteristics of Participants

\begin{tabular}{|c|c|c|c|c|c|c|}
\hline \multirow[t]{2}{*}{ Demographic characteristics } & \multicolumn{2}{|c|}{ Experimental } & \multicolumn{2}{|c|}{ Control } & \multicolumn{2}{|c|}{ Full sample } \\
\hline & $n$ & $\%$ & $n$ & $\%$ & $n$ & $\%$ \\
\hline \multicolumn{7}{|l|}{ Gender } \\
\hline Female & 11 & 45 & 16 & 80 & 27 & 67.5 \\
\hline Male & 9 & 55 & 4 & 20 & 13 & 32.5 \\
\hline \multicolumn{7}{|l|}{ Highest educational level } \\
\hline Some High school & 1 & 5 & 2 & 10 & 3 & 7.5 \\
\hline High school & 11 & 55 & 5 & 25 & 16 & 40 \\
\hline Bachelor's degree & 5 & 25 & 4 & 20 & 9 & 22.5 \\
\hline $\begin{array}{l}\text { Master's or professional } \\
\text { degree }\end{array}$ & 2 & 10 & 7 & 35 & 9 & 22.5 \\
\hline Doctorate or higher & 1 & 5 & 2 & 10 & 3 & 7.5 \\
\hline \multicolumn{7}{|l|}{ Ethnicity } \\
\hline White & 8 & 40 & 16 & 80 & 24 & 61.5 \\
\hline Black or African-American & 3 & 15 & 0 & 0 & 3 & 7.5 \\
\hline Latino or Hispanic & 5 & 25 & 2 & 10 & 7 & 15.0 \\
\hline Asian & 2 & 10 & 1 & 5 & 3 & 7.5 \\
\hline Middle Eastern & 1 & 5 & 0 & 0 & 1 & 2.5 \\
\hline Multiracial & 1 & 5 & 1 & 5 & 2 & 5 \\
\hline
\end{tabular}

Note. $N=40$ ( $n=20$ for each condition). Participants were on average 30.8 years old $(S D=$ 15.9), and participant age did significantly differ by condition. 
Table 2

Results of Differences across Groups

\begin{tabular}{|c|c|c|c|c|c|c|}
\hline \multirow[t]{2}{*}{ Logistic parameter } & \multicolumn{2}{|c|}{ Experimental } & \multicolumn{2}{|c|}{ Control } & \multirow[t]{2}{*}{$t(38)$} & \multirow[t]{2}{*}{$p$} \\
\hline & $M$ & $S D$ & $M$ & $S D$ & & \\
\hline Gender & 1.55 & .51 & 1.80 & .41 & -1.70 & .09 \\
\hline Age & 25.4 & 6.20 & 36.3 & 20.44 & -2.28 & .03 \\
\hline Personal control G1 & 52.85 & 6.84 & 53.00 & 7.33 & -.06 & .94 \\
\hline Interpersonal control G1 & 47.05 & 8.04 & 49.25 & 9.90 & -.77 & .44 \\
\hline Socio-political control G1 & 37.65 & 6.45 & 43.90 & 6.71 & -3.01 & .005 \\
\hline Self-esteem G1 & 21.65 & 5.98 & 19.25 & 4.12 & 1.47 & .15 \\
\hline Personal control G2 & 52.50 & 8.29 & 53.42 & 6.91 & -.37 & .70 \\
\hline Interpersonal control G2 & 46.45 & 8.72 & 48.73 & 10.26 & -.75 & .45 \\
\hline Socio-political control G2 & 38.55 & 6.50 & 43.05 & 8.97 & -1.80 & .08 \\
\hline Self-esteem G2 & 21.85 & 5.93 & 19.73 & 4.39 & 1.25 & .21 \\
\hline Perceived stress T1 & 3.83 & 2.40 & 4.10 & 2.62 & -.32 & .74 \\
\hline Perceived stress T2 & 4.68 & 2.28 & 4.15 & 2.69 & .64 & .52 \\
\hline Perceived stress T3 & 4.64 & 2.54 & 4.05 & 2.41 & .70 & .48 \\
\hline Perceived stress T4 & 4.00 & 2.40 & 3.66 & 2.47 & .41 & .68 \\
\hline Positive affect $\mathrm{T} 1$ & 31.05 & 8.59 & 33.20 & 9.41 & -.75 & .45 \\
\hline Positive affect T2 & 32.50 & 8.91 & 33.75 & 11.16 & -.39 & .69 \\
\hline Positive affect T3 & 28.15 & 9.70 & 31.21 & 9.87 & -.96 & .34 \\
\hline Positive affect T4 & 27.45 & 9.71 & 32.52 & 11.26 & -1.50 & .14 \\
\hline
\end{tabular}


Table 2 continued

Results of Differences across Groups

\begin{tabular}{lcccccc}
\hline \multicolumn{1}{c}{ Logistic parameter } & \multicolumn{2}{c}{ Experimental } & \multicolumn{2}{c}{ Control } & \multirow{2}{*}{$t(38)$} & \\
& \multicolumn{1}{c}{$M$} & $S D$ & $M$ & $S D$ & & .24 \\
\cline { 2 - 5 } Negative affect T1 & 17.00 & 7.56 & 14.60 & 5.12 & 1.17 & .09 \\
Negative affect T2 & 17.90 & 7.78 & 14.15 & 5.94 & 1.71 & .09 \\
Negative affect T3 & 18.42 & 10.63 & 13.94 & 4.12 & 1.71 & .13 \\
Negative affect T4 & 16.40 & 9.76 & 12.78 & 3.04 & 1.54 & .06 \\
Self-acceptance & 15.63 & 3.04 & 17.42 & 2.83 & -1.87 & .08 \\
Positive refocusing & 14.73 & 3.33 & 16.63 & 3.32 & -1.75 & .24 \\
Refocus planning & 15.63 & 3.21 & 16.73 & 2.49 & -1.18 & .29 \\
Positive reappraisal & 16.20 & 3.10 & 17.15 & 2.13 & -1.05 & .08 \\
Putting into perspective & 17.50 & 2.28 & 18.68 & 1.85 & -1.77 & \\
\hline
\end{tabular}




\section{Table 3}

Descriptive Statistics and Correlations for Study Variables

\begin{tabular}{|c|c|c|c|c|c|c|c|c|c|c|c|c|c|c|c|c|c|c|}
\hline Variable & $n$ & M & 50 & 1 & 2 & 3 & 4 & $s$ & 6 & 7 & 8 & 9 & 10 & 11 & 12 & 13 & 14 & 15 \\
\hline 1. Age & 40 & 30.85 & 15.9 & & & & & & & & & & & & & & & \\
\hline 2. Gender ${ }^{2}$ & 40 & 1.88 & $0.4 \mathrm{~s}$ & .14 & & & & & & & & & & & & & & \\
\hline 3. Personal control & 40 & 52.92 & 7.00 & .07 & -09 & & & & & & & & & & & & & \\
\hline $\begin{array}{l}\text { 4. Interpersonal } \\
\text { control }\end{array}$ & 40 & 48.10 & 8.98 & 22 & .14 & $53^{* *}$ & & & & & & & & & & & & \\
\hline $\begin{array}{l}\text { S. Socio-poditical } \\
\text { comeral }\end{array}$ & 40 & $40 . \pi 7$ & 7.23 & .04 & .21 & 24 & .21 & & & & & & & & & & & \\
\hline 6. Self-esteem & 40 & 20.45 & $\operatorname{s.22}$ & $-34^{*}$ & -04 & $-44 * *$ & $-62 *$ & -.16 & & & & & & & & & & \\
\hline 7. Self-acepeptince & 38 & 16.52 & 3.03 & .21 & .09 & $\omega 2$ & .26 & .14 & -.21 & & & & & & & & & \\
\hline 8. Positive refocusing & 38 & 15.88 & 3.41 & .10 & .01 & .18 & $.3 s^{\circ}$ & 24 & $-54 * *$ & $.44 *$ & & & & & & & & \\
\hline 9. Refocus planning & 38 & 15.18 & 2.89 & as & .26 & 21 & .12 & 31 & $-38^{*}$ & $.36^{\circ}$ & $.5 \mathrm{~s}^{*+4}$ & & & & & & & \\
\hline $\begin{array}{l}\text { 10. Phsitive } \\
\text { reapgraisal }\end{array}$ & 39 & 16.64 & 2.68 & .11 & $-0 s$ & $.46 * *$ & $.48 *-$ & 27 & $.05 \%$ & $.47 * *$ & $.61 * *$ & $\cos 4$ & & & & & & \\
\hline $\begin{array}{l}\text { 11. Putting into } \\
\text { perspective }\end{array}$ & 39 & 18.07 & 2.14 & 22 & -.13 & .11 & .16 & .19 & $-32^{*}$ & $69 *$ & $A 2 * 4$ & $50^{*}$ & $-4^{* *}$ & & & & & \\
\hline 12 Mearing made & 39 & 1.15 & .37 & 22 & $-\infty 2$ & .11 & .17 & 24 & -.13 & .04 & .15 & .07 & .14 & .12 & & & & \\
\hline 13. Negative affest & 40 & . $6 \mathrm{~s}$ & 4.39 & -.20 & -01 & -25 & $-399^{*}$ & -.15 & $.62 *$ & -21 & $-s i n$ & $-.54 * *$ & $-4 s^{* *}$ & .23 & -.04 & & & \\
\hline 14. Pasitive affect & 40 & -3.47 & 7.25 & $.32^{\circ}$ & .28 & 23 & $36^{\circ}$ & $\omega 2$ & $-41^{* *}$ & -.01 & .12 & .08 & $52^{* *}$ & .15 & -.04 & $\omega_{2}$ & & \\
\hline 15. Penceived stress & 37 & -.02 & 1.20 & -.31 & .09 & $-.20^{\circ}$ & $-39 *$ & .03 & $.59 *+$ & -.09 & $-.34^{*}$ & -31 & $-399^{\circ}$ & -208 & .18 & $.50 *$ & $-35^{*}$ & \\
\hline
\end{tabular}

Note: $\dagger$ indicates $p<.10 ; *$ indicates significance at the $p<.05$ level; ** indicates significance at the $p<.01$ level. ${ }^{\text {a }}$ Gender was coded 1=Men, $2=$ Women; ${ }^{\mathrm{b}}$ All measures are measures taken the first time at T1 or G1 


\section{Table 4}

Results of Within Subject Differences for Global Meaning in the Experimental Group

\begin{tabular}{lcccccc}
\hline \multicolumn{1}{c}{ Logistic parameter } & \multicolumn{2}{c}{$\mathrm{G} 1$} & \multicolumn{2}{c}{$\mathrm{G} 2$} & \multirow{2}{*}{$t(19)$} & $p$ \\
\cline { 2 - 5 } & \multicolumn{1}{c}{ M } & SD & $M$ & $S D$ & & \\
\hline Personal control & 52.85 & 6.84 & 52.50 & 8.29 & .36 & .71 \\
Interpersonal control & 47.05 & 8.04 & 46.45 & 8.72 & .44 & .66 \\
Socio-political control & 37.65 & 6.45 & 38.55 & 6.50 & -.75 & .45 \\
Self-esteem & 21.65 & 5.98 & 21.85 & 5.93 & -.36 & .71 \\
\hline
\end{tabular}

Table 5

Results of Within Subject Differences for Global Meaning in the Control Group

\begin{tabular}{lcccccc}
\hline \multicolumn{1}{c}{ Logistic parameter } & \multicolumn{2}{c}{$\mathrm{G} 1$} & \multicolumn{2}{c}{$\mathrm{G} 2$} & \multirow{2}{*}{$t(18)$} & \\
\cline { 2 - 5 } & \multicolumn{1}{c}{$M$} & $S D$ & $M$ & $S D$ & & \\
\hline Personal control & 53.15 & 7.50 & 53.42 & 6.91 & -.30 & .76 \\
Impersonal control & 49.84 & 9.81 & 48.73 & 10.26 & 2.31 & .66 \\
Socio-political control & 44.05 & 6.85 & 43.05 & 8.97 & .98 & .33 \\
Self-esteem & 19.00 & 4.08 & 19.73 & 4.39 & -1.73 & .10 \\
\hline
\end{tabular}




\section{Table 6}

Results of Within Subject Differences for Negative Affect in the Experimental Group

\begin{tabular}{|c|c|c|c|c|}
\hline Pair & $M$ & $S D$ & $T(19)$ & $p$ \\
\hline Pair 1 & & & -3.35 & .01 \\
\hline T3 PA & 28.16 & 9.70 & & \\
\hline $\mathrm{T} 2 \mathrm{PA}$ & 32.74 & 9.09 & & \\
\hline Pair 2 & & & 2.66 & .02 \\
\hline $\mathrm{T} 1 \mathrm{PA}$ & 31.05 & 8.59 & & \\
\hline $\mathrm{T} 4 \mathrm{PA}$ & 27.45 & 9.72 & & \\
\hline Pair 3 & & & 3.52 & .01 \\
\hline $\mathrm{T} 2 \mathrm{PA}$ & 32.50 & 8.91 & & \\
\hline T4 PA & 27.45 & 9.71 & & \\
\hline
\end{tabular}




\section{Table 7}

Repeated Measures One-Way Analyses of Variance on Stress and Affect Variables in the Experimental Condition

\begin{tabular}{lcccccc}
\hline \multicolumn{1}{c}{ Measure } & $M S$ & $d f$ & $F$ & $p$ & Green-house Geisser & Wilks' Lambda \\
\hline Negative affect & 14.82 & 3 & 2.25 & .12 & 24.43 & .70 \\
Positive affect & 105.86 & 3 & 3.84 & .03 & 170.55 & .58 \\
Perceived stress & 2.56 & 3 & 2.31 & .12 & 7.68 & .65 \\
Nervousness & .02 & 5 & 1.18 & .38 & .78 & .82 \\
Error & .27 & 16 & & & & \\
\hline
\end{tabular}




\section{Table 8}

Repeated Measures One-Way Analyses of Variance on Stress and Affect Variables in the Control

\section{Condition}

\begin{tabular}{lcccccc}
\hline \multicolumn{1}{c}{ Measure } & $M S$ & $d f$ & $F$ & $p$ & Green-house Geisser & Wilks' Lambda \\
\hline Negative affect & 5.73 & 3 & 2.39 & .10 & 10.30 & .69 \\
Positive affect & 23.45 & 3 & 1.23 & .33 & 70.36 & .81 \\
Perceived stress & .48 & 3 & 1.22 & .33 & .83 & .80 \\
Error & .57 & 16 & & & & \\
\hline
\end{tabular}

Note: The interactions are " 0 " since there was no variability in the experimental condition

\section{Table 9}

Moderator Analysis: Condition and Meanings Made on Negative Affect Difference Score (T3-

T2)

\begin{tabular}{lccccc}
\hline \multicolumn{1}{c}{ Variable } & $B$ & $95 \%$ CI & SE B & $F$ & $p$ \\
\hline Model & & & & .057 & .944 \\
Condition & & & & & \\
$\quad$ Experimental & .474 & $-1.62,2.57$ & 1.30 & & \\
$\quad$ Control & .968 & $-1.29,3.22$ & 1.11 & & \\
Meaning Made & & & & & \\
$\quad$ Yes & .621 & $-1.02,2.26$ & .812 & & \\
$\quad$ No & 1.16 & $-2.57,4.90$ & 1.84 & & \\
\hline
\end{tabular}

Note: The interactions are "0" since there was no variability in the experimental condition 


\section{Table 10}

Moderator Analysis: Condition and Meanings Made on Positive Affect Difference Score (T3-T2)

\begin{tabular}{lccccc}
\hline \multicolumn{1}{c}{ Variable } & $B$ & $95 \%$ CI & SE B & $F$ & $p$ \\
\hline Model & & & 1.27 & .292 \\
Condition & & & & \\
$\quad$ Experimental & -4.57 & $-7.93,-$ & 1.65 & & \\
$\quad$ & 1.22 & & \\
$\quad$ Control & -3.21 & $-6.81, .396$ & 1.77 & & \\
Meaning Made & & & & \\
$\quad$ Yes & -2.75 & $-5.38,-$ & 1.29 & & \\
$\quad$ & & & \\
$\quad$ No & -5.50 & -11.46, & 2.94 & & \\
& & .468 & & & \\
\end{tabular}

Note: The interactions are "0" since there was no variability in the experimental condition

\section{Table 11}

Moderator Analysis: Condition and Meanings Made on Perceived Stress Difference Score (T3-

T2)

\begin{tabular}{lccccc}
\hline \multicolumn{1}{c}{ Variable } & $B$ & $95 \%$ CI & SE B & $F$ & $p$ \\
\hline Model & & & & .346 & .710 \\
Condition & & & & & \\
$\quad$ Experimental & -.176 & $-.884, .531$ & .347 & & \\
$\quad$ Control & .042 & $-.687, .771$ & .358 & & \\
Meaning Made & & & & & \\
$\quad$ Yes & .037 & $-.513, .586$ & .270 & & \\
$\quad$ No & -.167 & $-1.35,1.02$ & .584 & & \\
\hline
\end{tabular}

Note: The interactions are " 0 " since there was no variability in the experimental condition 


\section{Figure 1}

The Meaning-Making Mode, Reprint of Park (2010)

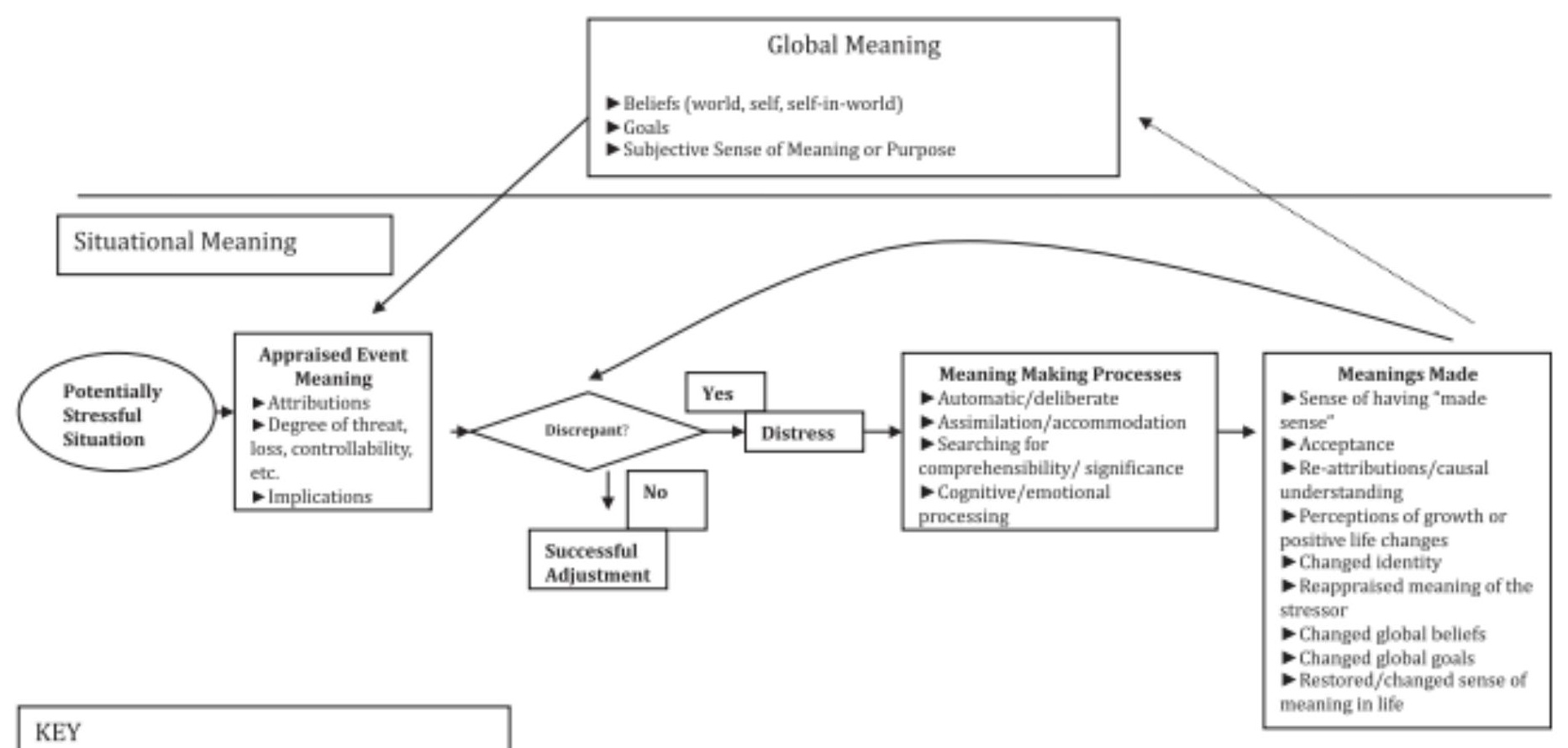

Critical model pathway

Possible model pathway 


\section{Figure 2}

Procedure Timeline for Each Group

\section{Experimental Group:}

\section{Measures:}

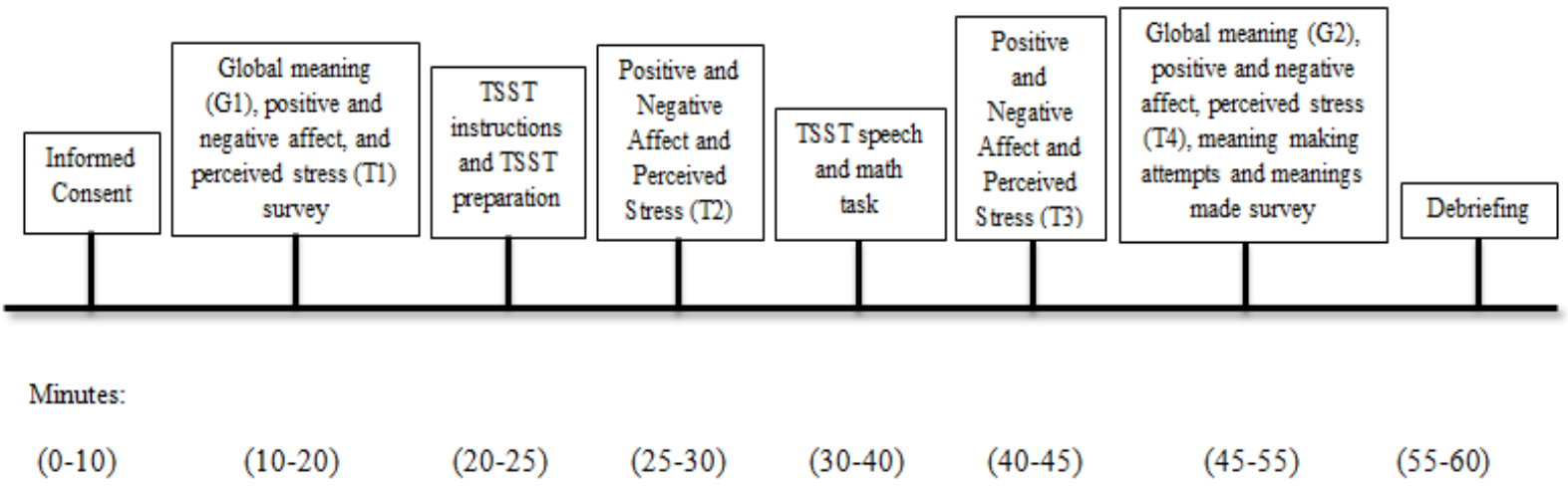

\section{Control Group:}

\section{Measures:}

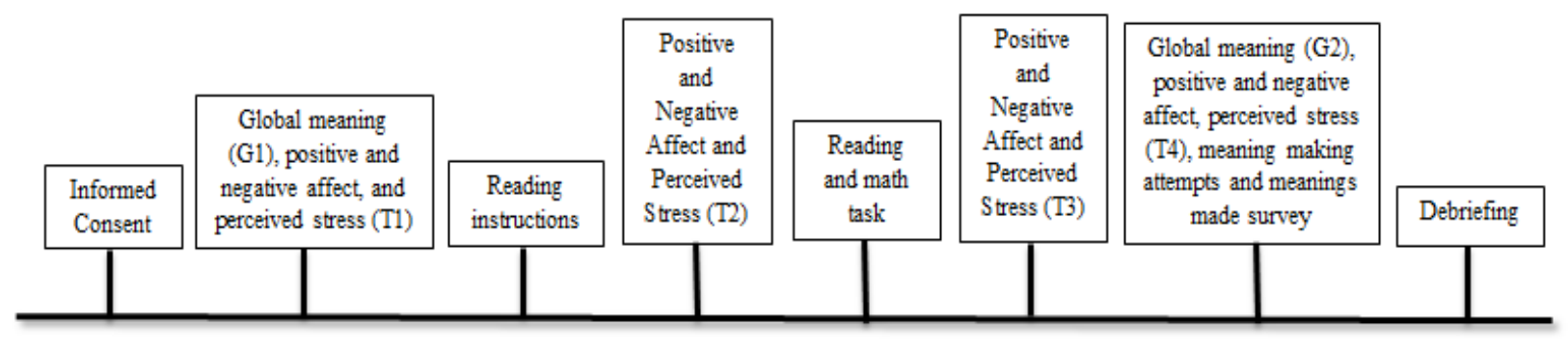

Minutes:

(10-20)

(20-25)

(25-30)

$(30-40) \quad(40-45)$

(45-55)

(55-60) 


\section{Figure 3}

Moderation Effect of Experimental Condition on Negative Affect Difference Score (T3-T2) by Meanings Made

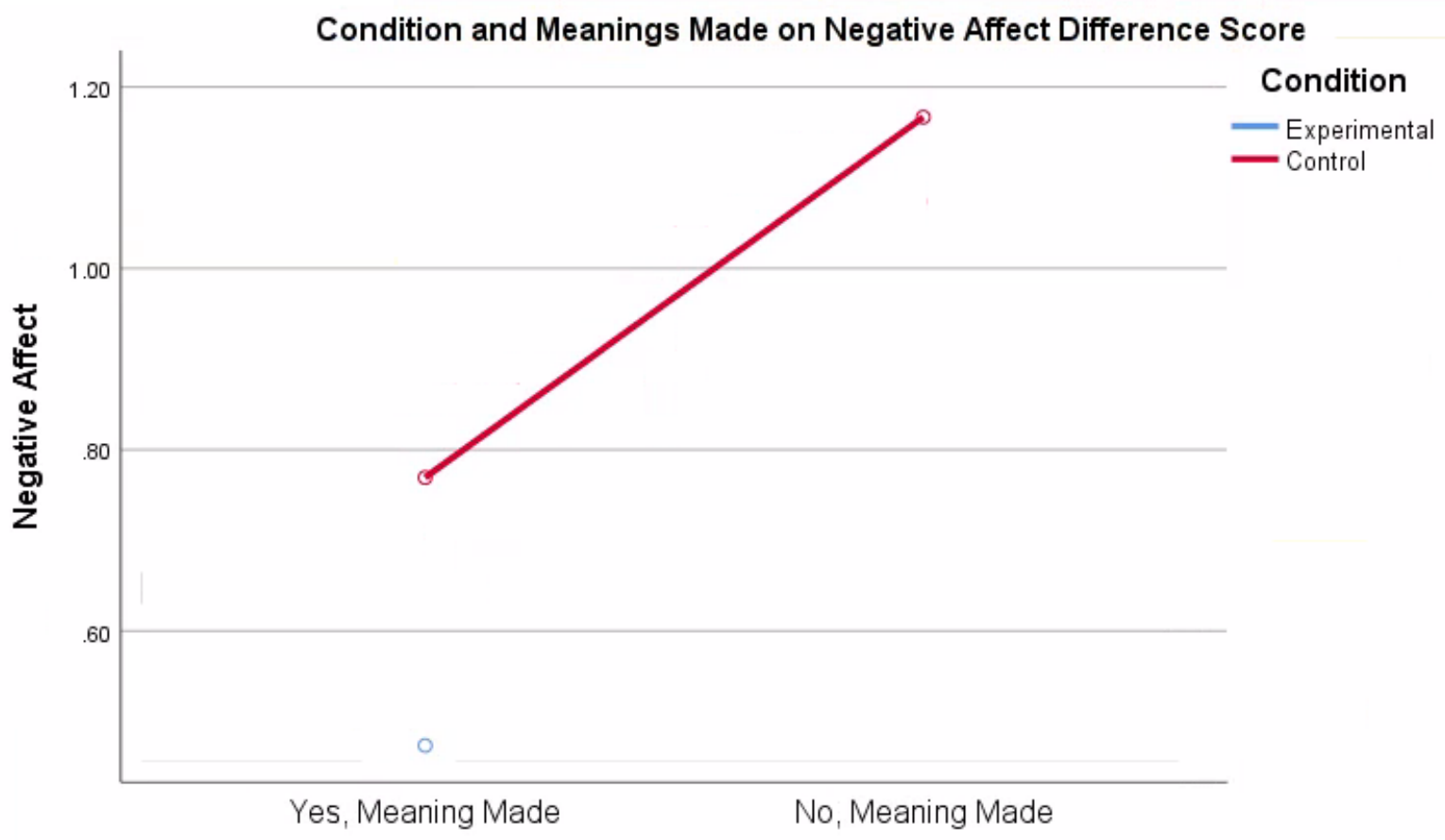




\section{Figure 4}

Moderation Effect of Experimental Condition on Perceived Stress Difference Score (T3-T2) by Meanings Made

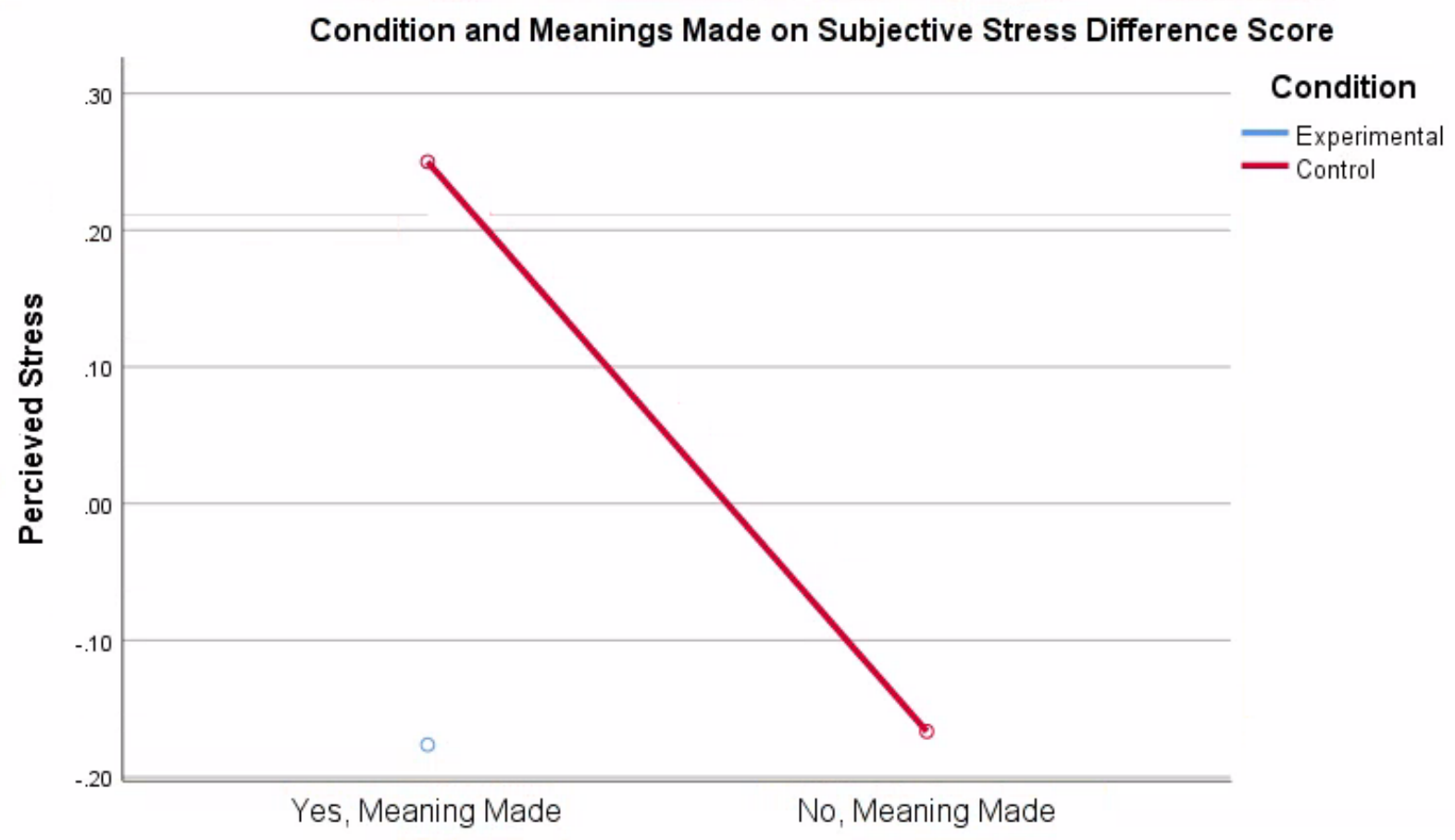




\section{Figure 5}

Moderation Effect of Experimental Condition on Positive Affect Difference Score (T3-T2) by Meanings Made

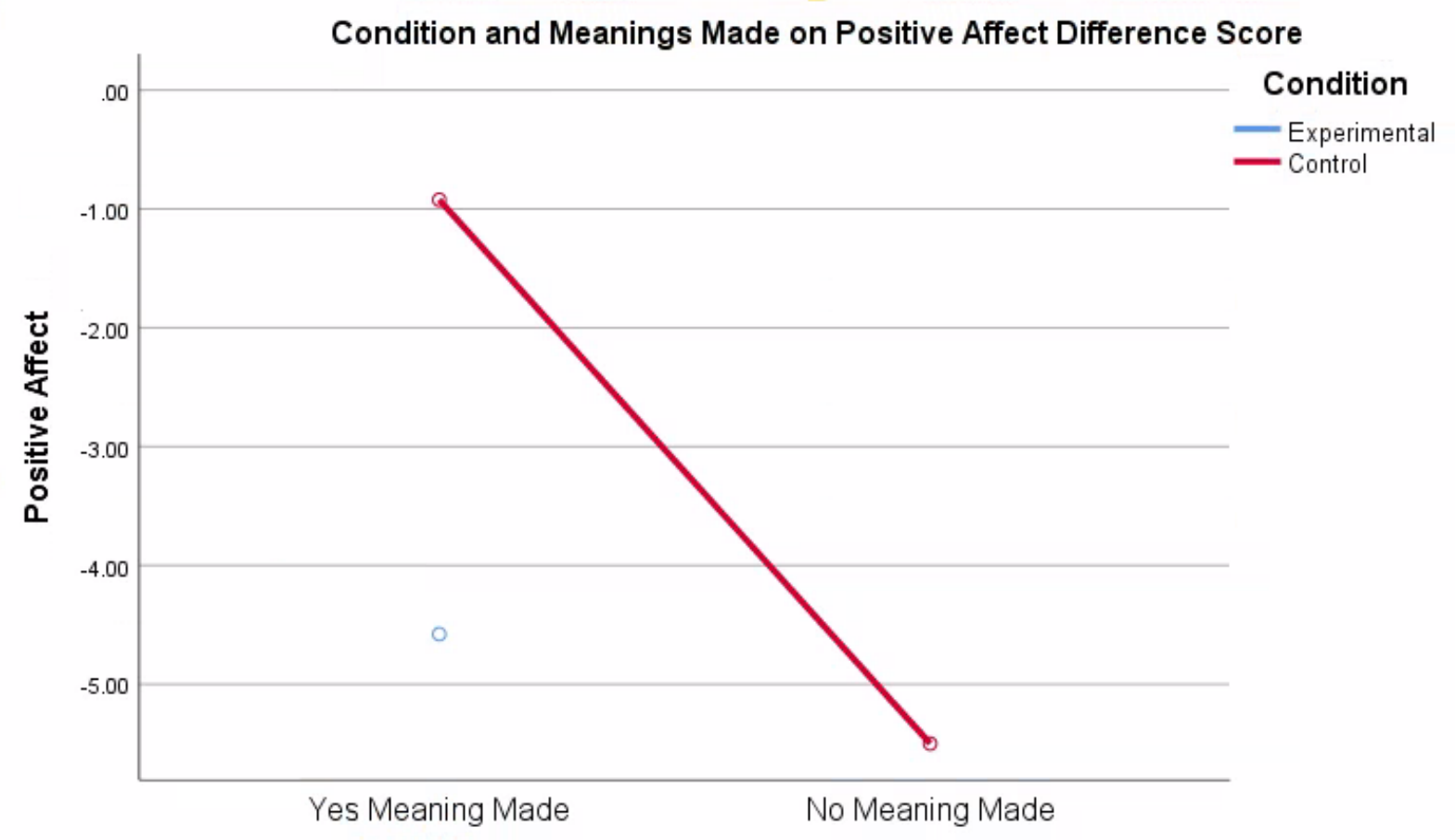




\section{Appendix A}

\section{Measures}

\section{Demographic questions:}

Q1 What is your age?

Q2 What gender do you identify as?

- Male

- Female

- Other

Q3 What is the highest degree or level of education you have completed?

- Some high school

- High school

- Bachelor's degree

- Master's or professional

- Doctorate or higher

Q4 Please specify your ethnicity

- White

- Black or African-American

- Latino or Hispanic

- Asian

- Native American

- Native Hawaiian or Pacific Islander

- Multiracial

- Other 


\section{Spheres of Control Scale}

Write a number from 1 to 7 to indicate how much you agree with each statement.

\begin{tabular}{ccccccc}
1 & 2 & 3 & 4 & 5 & 6 & 7 \\
Disagree & \multicolumn{1}{c}{ Neutral } & \multicolumn{1}{c}{ Agree }
\end{tabular}

1. I can usually achieve what I want if I work hard for it.

2. In my personal relationships, the other person usually has more control than I do.

3. By taking an active part in political and social affairs, we the people can influence world events.

4. Once I make plans, I am almost certain to make them work.

5. I have no trouble making and keeping friends.

6. The average citizen can have an influence on government decisions.

7. I prefer games involving some luck over games requiring pure skill.

8. I'm not good at guiding the course of a conversation with several others.

9. It is difficult for us to have much control over the things politicians do in office.

10. I can learn almost anything if I set my mind to it.

11. I can usually develop a personal relationship with someone I find appealing.

12. Bad economic conditions are caused by world events that are beyond our control.

13. My major accomplishments are entirely due to my hard work and ability.

14. I can usually steer a conversation toward the topics I want to talk about.

15. With enough effort we can wipe out political corruption.

16. I usually do not set goals because I have a hard time following through on them.

17. When I need assistance with something, I often find it difficult to get others to help.

18. One of the major reasons we have wars is because people don't take enough interest in politics. 
19. Bad luck has sometimes prevented me from achieving things.

20. If there's someone I want to meet, I can usually arrange it.

21. There is nothing we, as consumers, can do to keep the cost of living from going higher.

22. Almost anything is possible for me if I really want it.

23. I often find it hard to get my point of view across to others.

24. It is impossible to have any real influence over what big businesses do.

25. Most of what happens in my career is beyond my control.

26. In attempting to smooth over a disagreement, I sometimes make it worse.

27. I prefer to concentrate my energy on other things rather than on solving the world's problems.

28. I find it pointless to keep working on something that's too difficult for me.

29. I find it easy to play an important part in most group situations.

30. In the long run, we the voters are responsible for bad government on a national as well as a local level. 


\section{Rosenberg Self-Esteem Scale}

Below is a list of statements dealing with your general feelings about yourself. Please indicate how strongly you agree or disagree with each statement.
1. Strongly Agree
2. Agree
3. Disagree
4. Strongly Disagree

1. On the whole, I am satisfied with myself.

2. At times I think I am no good at all.

3. I feel that I have a number of good qualities.

4. I am able to do things as well as most other people.

5. I feel I do not have much to be proud of.

6. I certainly feel useless at times.

7. I feel that I'm a person of worth, at least on an equal plane with others.

8. I wish I could have more respect for myself.

9. All in all, I am inclined to feel that I am a failure.

10. I take a positive attitude toward myself.

\section{Stress Visual Analogue Scale}

Indicate how stressed you feel in the present moment by sliding the indicator below.

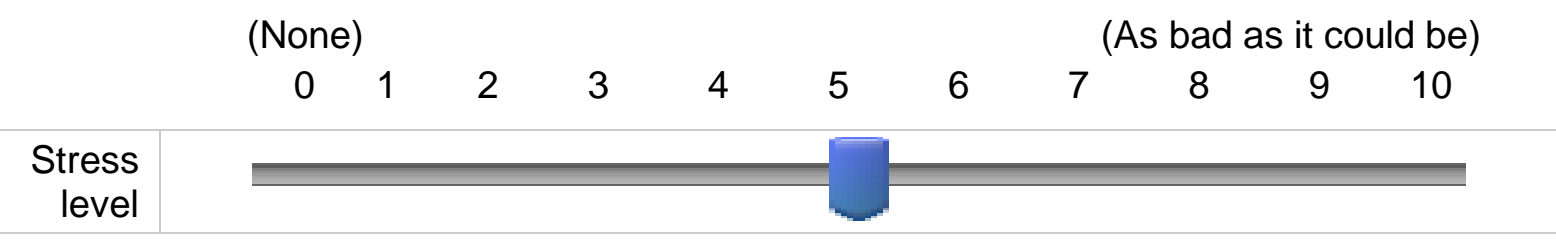


Positive and Negative Affect Schedule

Indicate the extent that you feel this way right now. 


\begin{tabular}{|c|c|c|c|c|c|}
\hline & $\begin{array}{c}\text { Very slightly } \\
\text { or not at all } \\
\text { (1) }\end{array}$ & A little (2) & $\begin{array}{c}\text { Moderately } \\
\text { (3) }\end{array}$ & $\begin{array}{l}\text { Quite a bit } \\
\text { (4) }\end{array}$ & Extremely (5) \\
\hline Interested & & & & & \\
\hline Distressed & & & & & \\
\hline Excited & & & & & \\
\hline Upset & & & & & \\
\hline Strong & & & & & \\
\hline Guilty & & & & & \\
\hline Scared & & & & & \\
\hline Hostile & & & & & \\
\hline Enthusiastic & & & & & \\
\hline Proud & & & & & \\
\hline Irritable & & & & & \\
\hline Alert & & & & & \\
\hline Ashamed & & & & & \\
\hline Inspired & & & & & \\
\hline Nervous & & & & & \\
\hline
\end{tabular}


Determined

Attentive

Jittery

Active

Afraid 


\section{TSST Instructions}

We will now assess how outgoing, gregarious, and comfortable you are in situations in which you must project yourself as an expert. This is a type of personality test for a trait called extraversion. Please read the hypothetical scenario below.

You have applied to your ideal job. You have dreamed about working in this job for as many years as you can remember. After submitting your application, you have been invited for an interview. You are competing against many other candidates. The final selection will be made based on your ability to convince the evaluator of how your experiences, abilities, and education make you a better candidate than the others. You will try to convince the evaluator that you are the best candidate for the position. The evaluator is specially trained to monitor and rate your speech for its believability and convincingness. They will compare your performance to that of the others who perform this task. You will be videotaped during the task, so our trained research team can later go over the videotape carefully and rate the contents of you speech and your nonverbal behavior.

You will fill out two more questionnaires and then you will be provided with a space to prepare your speech for the interview by taking notes for five minutes. Then you will go back to the Zoom meeting to give your speech to the interviewer.

\section{TSST Preparation}

Use the space below to prepare for your job interview speech. You will have five minutes to use the space below to write your thoughts down to use for your speech. 


\section{Cognitive Emotion Regulation Short Form}

Please state how you thought in the following manner while giving the speech you just gave to the interviewer.

$\begin{array}{ccccc}\begin{array}{c}\text { Strongly } \\ \text { disagree }\end{array} & \text { Somewhat } & 3 \text { Neither agree nor } & 4 \text { Somewhat } & 5 \text { Strongly } \\ \text { disagree } & \text { disagree } & \text { agree } & \text { agree }\end{array}$

Q1 I think that I have to accept what happened and how it went

Q2 I think that I have to accept the situation and how well I did

Q3 I think that I cannot change anything about how it went

Q4 I think that I must learn to live with the outcome

Q5 I can think of nicer things than what I just experienced

Q6 I can think of pleasant things that have nothing to do with the interview

Q7 I can think of something nice instead of what happened

Q8 I can think about pleasant experiences

Q9 I can think of what I can do best going forward

Q10 I can think about how I can best cope with the situation if I feel stressed

Q11 I can think about how to change the situation

Q12 I can think about a plan of what I can do best

Q13 I think I can learn something from the situation

Q14 I think that I can become a stronger person as a result of the situation

Q15 I think that the situation has positive sides

Q16 I can look for the positive sides to the matter 
Q17 I think that it could have been much worse

Q18 I think that other people go through much worse experiences

Q19 I think that it hasn't been too bad compared to other things

Q20 There are worse things in life than this

\section{Meanings Made}

1. Even if giving the interview speech was stressful, do you believe that practicing your speech and interview skills today helps you for interviews in the future?

\section{Yes}

No, this is not applicable 


\section{Appendix B}

\section{CONSENT DOCUMENT}

\section{Rhode Island College}

\section{Finding Meaning from Stress}

This research is being conducted by Kristen Petagna, a graduate student in the Psychology Department at Rhode Island College under the supervision of Dr. Kymberlee O'Brien. The study will take approximately 60 minutes to complete. We are examining social stress and how someone can find meaning from stress. You are being asked to participate because you are 18 years of age or older. You must have access to Zoom

\section{Why this Study is Being Done (Purpose(s)}

We are interested in how stress may change and to assess how outgoing, gregarious, and comfortable you are in situations in which you must project yourself as an expert.

\section{What You Will Have to Do (Procedures)}

- You will be asked to join a secure Zoom meeting with a researcher who is a student at Rhode Island College.

- $\quad$ You will be asked to complete surveys that usually take about 10-15 minutes over Qualtrics. A link to the survey will be sent to you on the Zoom chat. The researcher will turn off their camera and mute their microphone while you take the surveys. The surveys ask you questions about your mood, stress level, self-esteem, and feelings of control. When you complete the surveys, you can let the researcher know you are done, and the researcher will turn their camera on and unmute their microphone to go over the next part of the study. 
- After completing the surveys, we will ask you to either speak for 5 minutes, like a job interview, with the researcher or read a text for 10 minutes. The researcher will evaluate your interview and will take notes. This is recorded so that we can later assess your talk. This is destroyed after viewing.

- We will ask you to complete more surveys that usually take about 10-15 minutes over Qualtrics. Another link will be sent to you over the Zoom chat. The researcher will turn off their camera and mute their microphone while you take the surveys. The surveys ask you questions about your mood, stress level, self-esteem, feelings of control, meaning making attempts, and meanings made. When you complete the surveys, you can let the researcher know you are done, and the researcher will turn their camera on and unmute their microphone to debrief you about the study.

\section{$\underline{\text { Risks or Discomforts }}$}

There are psycho-emotional risks associated with this study. For example, you may experience negative feelings or mild stress related to speaking at length about a topic. We ask that you please let us know if anything ever feels too stressful. We are studying acute stress, and some of the tasks may be challenging. Please tell the researcher if this ever seems too distressing. If this occurs, we encourage you to speak with the researcher about the surveys and feelings they may have brought up. We will end any tasks immediately to avoid any negative feelings if they arise. We do not expect the study to be more upsetting than a normal amount of stress-and acute stress is a primary measure in this study. If you have lingering bad feelings later, after the end of the

study, there are additional counseling resources for you on and off campus listed at the end of 
this document. Please note that services in the community may have a fee associated that will need to be paid by you. Only RIC students can use RIC counseling services.

\section{Benefits of Being in the Study}

There are no direct benefits to you.

\section{$\underline{\text { Incentives }}$}

You will be given course credit if you are a Rhode Island College psychology student in an introductory to psychology class and will receive one ticket entered into a lottery to win an Amazon gift card and if you are not a student in the Introduction to Psychology class at Rhode Island College you will receive two tickets entered into the lottery to win an Amazon gift card. There will be three drawings. The first personal randomly drawn will win a \$50 Amazon gift card. The second two people drawn will each receive a \$25 dollar Amazon gift card.

\section{Deciding Whether to Be in the Study}

Now that you know about the study, you can decide whether you want to continue and participate. Being in the study is your choice to make. Nobody can force you to be in the study. Even during the study, if something is unacceptable to you, please tell us immediately so that we can either correct the problem or stop the experiment. Please understand that your participation in the research is voluntary and that you are free to withdraw your consent and stop participation in the research at any time without any penalties. If you know now that you do not want to continue, please tell the researcher. 


\section{$\underline{\text { How Your Information will be Protected }}$}

Because this is a research study, results will be summarized across all participants and shared in reports that we publish and presentations that we give. Your name will not be used in any reports. We will take several steps to protect the information you give us so that you cannot be identified. Instead of using your name, your information will be given a code number. The only time I would have to share information from the study is if it is subpoenaed by a court, or if you are suspected of harming yourself or others, then I would have to report it to the suitable authorities. In addition, if there are problems with the study, the records may be viewed by the Rhode Island College review board responsible for protecting the rights and safety of people who participate in research. The information will be kept for a minimum of three years after the study is over, after which it will be destroyed.

\section{Who to Contact}

You can ask any questions you have now. If you have any questions later, you can contact Kristen Petagna at kpetagna_7859@email.ric.edu or Dr. Kymberlee O’Brien at kobrien@ ric.edu. If you think you were treated badly in this study, have complaints, or would like to talk to someone other than the researcher about your rights or safety as a research participant, please contact the IRB Chair at IRB@ ric.edu.

If you have lingering bad feelings later, after the end of the study and speaking with the researcher, these are additional counseling resources for you on and off campus:

On campus:

If you are a RIC Student and feel distressed, please call the 24/7 Rhode Island College HOPE line: (401) 456-HOPE (4673). 
RIC Counseling Center: Browne Hall, Suite 100, (401) 456-8094

RIC Health Services - Primary care health services for students at RIC, (401) 456-8055

On and Off campus:

Learning for Life - Connects students to peer advocates as well as other on-campus and offcampus resources, (401) 456-6320

National Suicide Prevention Lifeline

800.273.TALK(8255)

Please note that if you need immediate support, please dial 911 and proceed to your local emergency room.

You can print a copy of this form to keep.

I agree to be video recorded for the study: Yes No

\section{Statement of Consent}

I have read and understood the information above. I am choosing to be in the study Finding Meaning from Stress. I can change my mind and quit at any time, and I do not have to give a reason. I have been given answers to the questions I asked, or I will contact the researcher with any questions that come up later. I am at least 18 years of age.

I consent to participate in this study: Yes No 


\section{Appendix C}

\section{Experimenter Debriefing Script: Finding Meaning from Stress}

Thank you for participating in our study! How Did You Just Help Us Out?

In order to get natural responses from participants we don't fully explain what we are studying until the experiment is over. However, before I tell you more about the study, I'd like to gauge your initial reactions. What do you think was the point of the study? [to get a sense of what their overall impression is. Talk with the participant about what they experienced and how they are feeling. In particular, pay attention to any distress or negative responses; also probe for awareness of the study questions, that is, did they have an accurate guess on the point of the study.]

Let me tell more about the study: We are looking at how finding meaning from stress can influence mental health and possibly even change one's beliefs. Individuals are usually very good at preparing for an upcoming stressor, such as giving a speech, which is partly why we are vague on this point. We are assessing natural responses to acute stress in the hopes that we can better understand how social stressors- that are very real for most people-might influence their mood. Most people have a fear of public speaking and we are interested in measuring natural responses to stress, which is why we couldn't tell you about the speech or math task ahead of time. The video we recorded will not be used and will be deleted immediately.

It is very important for you to know that the evaluator in this study is a student member of our research team. Their behavior and comments throughout all aspects of the experiment were scripted. This means that in no way was their behavior a reflection of you, what they thought of you, or your performance. They are trained research assistants in our lab and are trained to make negative gestures while you are giving the speech. It is very normal to feel acute stress when being evaluated and while receiving little social feedback or negative feedback or to 
feel that you did not perform at your best. I can assure you that you did a great job and these tasks are intended to be challenging.

As for your data, your name and address will not be connected in any way with your data.

However, even at this point, you have the right to withdraw your participation and not permit us to use your data. Remember that no personally identifiable information will ever be associated with your data. In addition, all analyses of the data will be aggregated. We look at whole groups, not individual data.

You did a great job! Do you have any questions? Do you feel okay to leave? Thank you for your help in keeping things confidential - we really appreciate it!

If you are upset after completing the study and would like to talk to someone, you can use these resources:

- $\quad$ Crisis Text Line: Text CONNECT to 741741

- NAMI (National Alliance on Mental Illness) Helpline: Call 1-(800)-950-6284 or email info@nami.org

- Psychology Today Find a Therapist: psychologytoday.com/us/therapists

- If you are a RIC Student and feel distressed, please call the 24/7 Rhode Island College HOPE line: (401) 456-HOPE (4673).

- $\quad$ RIC Counseling Center: Browne Hall, Suite 100, (401) 456-8094

- $\quad$ RIC Health Services - Primary care health services for students at RIC, (401) 456-8055

- On and Off campus:

- Learning for Life - Connects students to peer advocates as well as other on-campus and offcampus resources, (401) 456-6320 